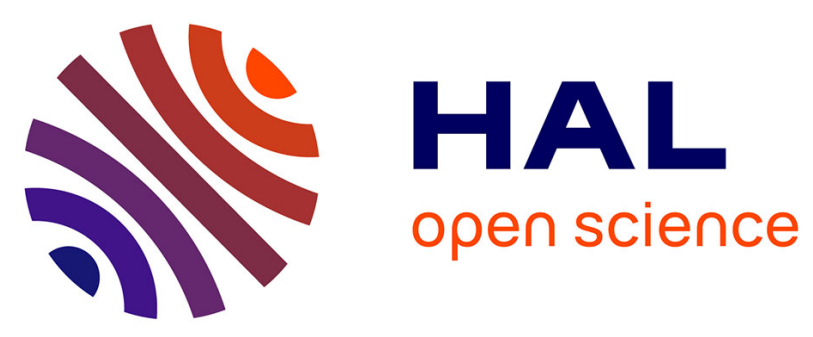

\title{
Mechanism of porosity formation and influence on mechanical properties in selective laser melting of Ti-6Al-4V parts
}

Jonathan Stef, Angeline Poulon-Quintin, Abdelkrim Redjaïmia, Jaafar Ghanbaja, Olivier Ferry, Matthias de Sousa, Mohamed Gouné

\section{To cite this version:}

Jonathan Stef, Angeline Poulon-Quintin, Abdelkrim Redjaïmia, Jaafar Ghanbaja, Olivier Ferry, et al.. Mechanism of porosity formation and influence on mechanical properties in selective laser melting of Ti-6Al-4V parts. Materials \& Design, 2018, 156, pp.480-493. 10.1016/j.matdes.2018.06.049 . hal01874197

\section{HAL Id: hal-01874197 https://hal.science/hal-01874197}

Submitted on 10 Oct 2018

HAL is a multi-disciplinary open access archive for the deposit and dissemination of scientific research documents, whether they are published or not. The documents may come from teaching and research institutions in France or abroad, or from public or private research centers.
L'archive ouverte pluridisciplinaire HAL, est destinée au dépôt et à la diffusion de documents scientifiques de niveau recherche, publiés ou non, émanant des établissements d'enseignement et de recherche français ou étrangers, des laboratoires publics ou privés. 


\section{Mechanism of porosity formation and influence on mechanical properties in selective laser melting of Ti-6Al-4V parts}

Stef J. ${ }^{1,3}$, Poulon-Quintin A. ${ }^{1}$, Redjaimia A. ${ }^{2}$, Ghanbaja J. ${ }^{2}$, Ferry O. ${ }^{2}$, De Sousa M. ${ }^{3}$, Gouné M. ${ }^{1}$

1. CNRS, ICMCB, Univ. Bordeaux, Pessac, France

2. Institut Jean Lamour, UMR 7198 CNRS, Université de Lorraine, Parc de Saurupt, 54011 Nancy Cedex, France

3. WeAre-3D Materials, Centre Européen de la Céramique, 12 rue Atlantis, 87068 Limoges, France

\section{Abstract}

An original approach based on 2D fracture surface and 3D X-ray tomography analysis is proposed in this paper. Its application in selective laser melting of Ti-6Al-4V provides substantive clarifications regarding both mechanisms of porosity formation and their influence on mechanical properties. Unambiguously, a one-toone relationship between the scanning strategy pattern and the 3D spatial distribution of porosities is highlighted. In an original manner, the 3D location of porosities, their morphology and their orientation are analyzed with respect to the laser spot path. The results show that pores are mainly localized on the overlay zones and support the lack of energy induced by the lower energy at the periphery of the laser spot as the main mechanism of porosity formation. Finally, both tensile properties and crack path are shown to be influenced by the presence and 3D distribution of porosities.

\section{Introduction}

Selective Laser Melting (SLM) or Direct Metal Laser Sintering (DMLS) is an additive manufacturing process based on powder bed fusion (PBF) and widely studied in recent years for the production of metallic parts, from pure Ti, Ti alloys, Al alloys, steels and so on [[1], [2], [3], [4], [5], [6], [7], [8], [9], [10], [11]]. A 3D component is built by selectively melting powders within and between layers. The heat source is a finely focused laser. This technology, of considerable importance due its potentially cost effectiveness, low material waste and possibilities it offers to produce complex-shapes components meets a growing success in the aerospace industry $[12,13]$. In particular, the $\mathrm{Ti}-6 \mathrm{wt} \% \mathrm{Al}-4 \mathrm{wt} \% \mathrm{~V}$ alloy is of interest owing to its high corrosion resistance and high specific strength [14]. However, actual knowledge on the SLM process remains insufficient and hinders its development on a larger scale [11, 15, 16].

Among the possible reasons, the control of properties of manufactured products is made difficult since it depends on many complex interactions between the input powders, the process and microstructural parameters, the metallurgical defects and the mechanical properties [7, 8, 15, [17], [18], [19], [20], [21], [22], [23]]. In that context and although SLM of Ti-6Al-4V has made significant advances in the process optimization, built materials are often subject to inner defects or local irregularities which influence their properties. Their role upon mechanical properties was clearly suspected. In attendance of porosity, the ultimate tensile strength, elongation, Young's modulus and fatigue performance were shown to be deteriorated [19, [24], [25], [26]]. The anisotropy of tensile properties can also be attributed to the orientation of defects with respect to the loading direction [27, 28]. If defects are perpendicular to the 
loading direction, they are expected to open up at relatively low stress levels. Otherwise, if they are parallel to the tensile loading axis, their opening becomes more difficult. Furthermore, although the presence of porosity was shown to influence both fracture and fatigue properties, the mechanisms of crack initiation and propagation remain unclear $[19,29]$. It was observed that cracks initiate from voids in the subsurface and propagate radially outwards $[19,30]$. Melt pool boundaries were evidenced as potential sites for crack propagation [31], while no influence where evidenced by Konecnà et al. [32].

Regarding the mechanisms of porosity formation, several sources of porosities were identified i.e. (1) unmelted or partially melted powder particles (2) lack of fusion (3) delamination between adjacent passes or previous deposited layers (4) entrapment of gases during manufacturing [2, [33], [34], [35], [36], [37]]. Porosity is usually correlated to the process parameter "energy density" $E_{v}$, defined by the ratio of laser power $(P)$ to scanning velocity $(v)$, hatch spacing $(h)$ and layer thickness $(I)[7,8,31,33,35]$ :

$$
\mathbf{E}_{\mathbf{v}}=\frac{\mathbf{P}}{\mathbf{v} \cdot \mathbf{l} \cdot \mathbf{h}},\left[\mathrm{J} / \mathrm{mm}^{3}\right]
$$

While imperfect, the use of volume energy is certainly the most established approach to control the process/porosity relationship. An increase of porosity due to keyholing is expected at high energy density (high laser power and low scan rate), while an increase of porosity due to incomplete melting or "lack of fusion" is expected at lower energy density (low laser power and high speed) and a minimum of porosity is expected at intermediate energy density. A classification for the SLM process window was thus proposed. Depending on the laser power and scan rate, different zones were identified corresponding to fully dense material, incomplete melting, over-melting and overheating [19, 35, 37].

The development of new advanced techniques opens up new opportunities to obtain 3D quantitative data with the objective to improve our understanding about the dynamic of porosity formation and to identify critical defects [33]. For instance, very recently, the analysis of voids performed by using synchrotron X-ray tomography suggests that 3D topology and morphology are indicators of their formation. Indeed, near spherical defects were associated to an excessive energy density while the elongated voids oriented preferably perpendicularly to the building direction were associated to a lack of fusion [33, 37]. However, it is believed that the topological and morphological criteria do not in themselves constitute a formal evidence of the porosity formation mechanism. The 3D spatial distribution with respect to the real laser path is also expected to be an indicator. However, this information is very difficult to obtain because it would require collecting data from the laser path and the porosity formation in real time and in-situ. In this paper, an original approach based on 2D fracture surface and 3D X-ray tomography analysis is proposed. Its application in SLM of Ti-6Al-4V provides substantive clarifications regarding both the 3D location of porosities with respect to the laser spot path and the mechanism of porosity formation. Also, the 3D view of the fracture surface of the broken tensile sample coupled with the 3D distribution of porosities gives additional information regarding the potential sites for crack initiation and propagation.

\section{Materials, tools and method}

\subsection{Ti-6Al-4V input powder}

Titanium Ti-6Al-4V (Ti - $6 \mathrm{wt} \% \mathrm{Al}-4 \mathrm{wt} \% \mathrm{~V}$ ) powder feedstock from Tekna and produced by plasma atomization was used in this study. In Fig. 1a the micrograph obtained by scanning electron microscopy on the TESCAN VEGA 2 equipment shows that the Ti-6Al-4V powders have a spherical shape. Particle size 
distribution (Fig. 1b) was measured by laser diffraction using a Malvern instruments - MasterSizer 2000. It was found that the median particle size was $11 \mu \mathrm{m}$, the $D_{10}$ was $7 \mu \mathrm{m}$ and the $D_{90}$ was $18 \mu \mathrm{m}$.

Chemical composition of the input powder was determined by ICP-OES analysis (Varian ICP/OES 720 ES) for $\mathrm{Al}, \mathrm{V}, \mathrm{Fe}$ elements and by Inert gas fusion analysis for $\mathrm{O}$ and $\mathrm{H}$ light elements. The chemical composition, given in Table 1, is in the allowance defined by the ASTM B348 standard [38].

\subsection{Elaboration of Ti-6Al-4V samples by SLM and machining of tensile specimens}

Parts with a dimension of $90 \times 6 \times 23 \mathrm{~mm}$ were manufactured by SLM using the 3D Systems ProX DMP 100 equipment (Fig. 2a). No heating of the base plate was done. The $x, y$ and $z$ axes represent the powder loading direction, the axis of the roller and the layer stacking direction respectively (Fig. $2 \mathrm{~b}$ ). All parts were built in a protective Argon atmosphere and the main process parameters are summarized in Table 2 . They were directly taken from the data base of the company who manufactured these parts. The complete analysis of this data base showed that different process parameters (laser power $\mathrm{P}$, laser scanning speed $\mathrm{v}$ ) leading to the same energy density of about $50 \mathrm{~J} / \mathrm{mm}^{3}$ can be used. It was shown that the volume fraction and the number of voids per volume depend on $P$ and $v$ while $E$ is constant. For the same value of $E=50 \mathrm{~J} / \mathrm{mm}^{3}$, three possible scenarios can be distinguished depending on the value of $P$ and v: very few defects, limited number of defects and significant amount of defects. The parts with limited number of defects were chosen in order to enhance our conclusions since it is a very tedious process to make general statements when the porosity is low or very important. However, all the conclusions we will draw remain still valid when porosity is low or important.

The scanning strategy, given in Fig. $2 \mathrm{~b}$, consists of straight lines with a $90^{\circ}$ rotation between each layer. It is worth noting that no thermal treatment was done subsequent to the as-build part manufacturing.

\subsection{Tensile test}

In order to characterize the tensile behavior of the manufactured parts, two flat tensile specimens with a thickness of $2 \mathrm{~mm}$ were sampled by an electrical discharge machining process after removing the rough surface. The dimensions of the tensile specimens and their sampling locations are presented in Fig. 3 . Tensile tests were performed with an Instron 3369 Dual column testing systems along the $x$-direction, with a displacement speed $0.1 \mathrm{~mm} \cdot \mathrm{s}^{-1}$.

\subsection{Microstructural characterization}

\subsubsection{Observation and analysis of phases}

Microstructural characterizations were conducted by using both SEM and TEM. The SEM microstructural observations of the as-built Ti-6AI-4V samples were performed on a JEOL - JSM 6360 scanning electron microscope. The sample was first mirror mechanically polished and then a final polishing step with a solution consisting of $50 \%$ OPS $+47 \% \mathrm{H}_{2} \mathrm{O}+3 \% \mathrm{H}_{2} \mathrm{O}_{2}$ is realized.

It was finally etched for 2 min with a mixture containing $9 \% \mathrm{KOH}+5 \% \mathrm{H}_{2} \mathrm{O}_{2}+86 \% \mathrm{H}_{2} \mathrm{O}$. Transmission electron microscopy (TEM) investigations were carried out using a JEM - ARM 200F Cold FEG TEM/STEM operating at $200 \mathrm{kV}$ and equipped with a spherical aberration (Cs) probe and image correctors. A rectangular flat sample was first mechanically polished to a thickness of $80 \mu \mathrm{m}$ and cut in disc of $3 \mathrm{~mm}$ of diameter. The disc was then ion milled for direct observations (Pips, GATAN). 
For clarity, a schematic representation of specimens sampled from the same manufactured part is showed in Fig. 4. The analysis of the nature of the phases formed was performed by SEM and TEM on the (YZ) plane cross section of an as-built sample named "MP-YZ" sample and represented in Fig. 4.

\subsection{2. $2 \mathrm{D}$ porosity analysis}

In this paper, the terms porosity, pore and void will be used to designate the same object i.e. the defects generated during SLM manufacturing.

The MP-XY and FS-XY samples were considered (Fig. 4) for the 2D porosity analysis on the (XY) plane mechanically polished surface and the (XY) fracture surface. Porosities can be recognized by dark areas pointed by arrows on the SEM image given in Fig. 5. The measurements of surface void fraction were performed using classic image treatment with the image J software. The total surface area analyzed is $47 \mathrm{~mm}^{2}$. Only the bottom part of the broken specimen is studied as it allows to correctly observe the laser tracks contained on the fracture surface, non-existent on the top part. Besides, because of the polishing steps, the observation of laser tracks contained in pores belonging to the cross-section is made difficult. Laser tracks correspond to a matter discontinuity, and therefore are assimilated to voids. Considering these remarks, voids were one by one identified and selected from SEM micrographs of FS-XY sample's fracture surface with the "ROIManager" ImageJ Software's tool as represented Fig. 6a by the red area. Void surface area was then calculated using the ImageJ Software from a total (XY) plane surface area of $42 \mathrm{~mm}^{2}$.

As the laser tracks is a marker of the laser path, by direct observations of laser tracks within each void and knowing the characteristic lengths of the scanning strategy, it is possible to deduce the laser path and direction as represented in Fig. 6 a by blue dotted lines and green arrows i.e. the scanning strategy. The overlay zones are defined as the overlap regions between two successive laser paths and can be represented by the green volume in Fig. $6 \mathrm{~b}$. The axis of symmetry of the overlay zones are represented by the black lines in Fig. 6a and b.

Fig. 7 shows the SEM micrograph of the last deposited layer (LDL sample) of an as-built SLM part. One melt pool track has a width measured up to $120 \mu \mathrm{m}$. The distance between two laser paths is $70 \mu \mathrm{m}$, so the width of the overlay zone represented by the green area is estimated to be around $50 \mu \mathrm{m}$. The axis of symmetry of the overlay zone is represented by the black line. In the results part, only the axis of symmetry of the overlay zone will be represented.

As represented in Fig. 8, two types of layers can be distinguished. First, the N-1 layer, defined as the layer delimited by the laser track observable at the bottom of the considered void. It corresponds to the layer anterior to its formation. Second, the $\mathrm{N}$ layer, defined as the layer following the $\mathrm{N}-1$ deposited layer in which the considered void starts to be formed. As a consequence, a void can be located in four different locations labeled by the numbered black crosses in Fig. 9: (1) in the N-1 projected overlay zone, (2) in the N overlay zone, (3) both in the N and N-1 projected overlay zone and (4) outside of an overlay zone.

In order to determine the location of a void, the $\mathrm{N}-1$ direction has to be first determined. It corresponds to the laser path direction in the $\mathrm{N}$-1 layer, i.e. the direction of the visible laser track. The $\mathrm{N}$ direction is then found from the perpendicular to the $\mathrm{N}-1$ direction. Based on this and from both the reconstructed scanning strategy (Fig. 6a) and the width measurement of the overlay zone (Fig. 7), it is then possible to determine each void location with respect to the laser path and to conclude to the presence of voids either in the overlay zones or in the laser path zone. Fig. 10 gives an example of the four types of void location. The frequency and number of voids were then statistically analyzed as a function of both their location and morphology. 


\subsubsection{D void and fracture surfaces analysis}

A Phoenix Nanotom X-ray micro-computed tomography ( $\mu \mathrm{CT}$ ) equipment was used to characterize the void morphology and distribution in both the as-built samples and broken samples after tensile test performed along the $x$-direction. Specimens with $10 \mathrm{~mm} \times 2 \mathrm{~mm} \times 2 \mathrm{~mm}$ dimensions were extracted from a tensile sample before and after tensile test. They are represented in Fig. 4 and will be called YZO and FS-YZ respectively in the following.

The $\mu \mathrm{CT}$ equipment was composed of an X-ray tube operating up to $180 \mathrm{kV} / 15 \mathrm{~W}$ and an X-ray scintillator screen which was coupled to a high-resolution Hamamatsu CCD-sensor (2300 pixels $\times 2300$ pixels). The $\mu C T$ procedure was based on the acquisition of a series of X-ray radiographs of a sample that rotated step by step around a vertical axis perpendicular to the incident beam. Images were recorded over a period of $6 \mathrm{~s}: 6$ times for each one $(6 \times 750 \mathrm{~ms})$ and 2 times $(2 \times 750 \mathrm{~ms})$ with the detector turn off to obtain an average one, with a step of $0.25^{\circ}$ for each radiography. 1440 images were recorded for a total time of scan of $144 \mathrm{~min}$. An energy of $80 \mathrm{keV}, 80 \mu \mathrm{A}$ was used with a microfocus beam of $2 \mu \mathrm{m}$. For 3D-imaging reconstruction, a mathematical algorithm (cone-beam algorithm of Feldkamp) was used to reconstruct the distribution of absorption coefficients within the sample volume using datos/x reconstruction software, and then the internal 3D volume structure of the samples. The final resolution of the 3D-images was voxels of dimensions $2 \times 2 \times 2 \mu \mathrm{m}^{3}$.

The 3D representation of the fracture surface was obtained by importing the ".raw" file in the 3D software (VGStudio Max 2.2 and AVIZO 8.0) whereas some additional steps were necessary to represent voids in the material. In order to distinguish voids from the Ti-6Al-4 V material with accuracy, some filters were applied (adaptive gauss and opacity mapping filters) on each (XY) oriented slices with the ImageJ software. Firstly, slices were rescaled, then the "normalize local contrast" Integral image filter and the mean filter were applied. Finally, the slices were threshold to keep only voids. However, it is very difficult to reconstruct voids in the immediate vicinity of the fracture surface as a result of numerous artefacts, the rough aspect of the given zone including also the presence of cracks. In order to study the path of cracks with respect to the void distribution, a dual-representation composed of the fracture surface at the top part and the void representation at the bottom part was used. The two parts were properly superimposed by matching some common slices as explained in Fig. 11.

The morphological quantification of voids was performed on the ImageJ software with the "3D Object counter" module, whereas the slices were imported into the AVIZO 8.0 software for the 3D representation of voids. The equivalent diameter was calculated by the classical following formula:

$$
D_{e q}=\sqrt[3]{\frac{6 \cdot V}{\pi}}
$$

where $V$ is the volume of the 3D particle. The shape factor parameter was defined by:

$$
S F=\frac{\mathrm{d}_{\max }}{\mathrm{d}_{\min }}
$$


where $d_{\max }$ and $d_{\min }$ are respectively the largest and the smallest length of the 3D particle.

Finally, the 3D graphic representation of the scanning pattern was modelized using the Dassault systems CATIA V5 CAO Software.

\section{Results and discussion}

\subsection{Microstructure of as built Ti-6Al-4V parts and $\mu \mathrm{CT}$ analysis}

SLM can be seen as a very rapid solidification process. Indeed, the cooling rate in the melt pool of Ti-6Al-4V is one of the main parameters controlling subsequent phase transformation to room temperature. It was estimated to be $10^{5} \mathrm{C} / \mathrm{s}$ [12]. During cooling, Ti-6Al-4V solidifies first as a bcc $\beta$-Ti. The corresponding macrostructure of solidification, composed of both columnar and equiaxed grains (Fig. 12), was observed for relatively high values of both solidification rate velocity and thermal gradient [12]. The presence of numerous needles of different size was highlighted in the microstructure at a finer scale and is typical of the displacive transformation of $\beta-\mathrm{Ti}$ to hcp- $\alpha^{\prime}$ martensite upon cooling. The high cooling rate reached in SLM is much higher than the critical cooling rate of about $410^{\circ} \mathrm{C} / \mathrm{s}$ required for the martensite formation [39]. The combined analysis using high resolution TEM and Fast Fourier Transform (FFT) confirms the presence of martensite having an hexagonal crystalline structure with lattice parameters $a=0.252 \mathrm{~nm}, b=0.222 \mathrm{~nm}$ and $c=0.467 \mathrm{~nm}$.

The 3D $\mu C T$ view of voids in the as-built sample is given in Fig. 13a. Voids are represented in green. The $x, y$ and z-dimensions of the represented volume are respectively $1.812 \mathrm{~mm}, 2.130 \mathrm{~mm}$ and $1.864 \mathrm{~mm}$. The volume fraction and the density of voids are found at 0.48 vol\% and 1866 particle $\cdot \mathrm{mm}^{-3}$ respectively. In this representation, no specific arrangement of voids can be seen. Fig. 13b gives the void size distribution in the as built material. The equivalent diameter of voids varies between $4 \mu \mathrm{m}$ and $40 \mu \mathrm{m}$. The median void size was $11 \mu \mathrm{m}$. The smallest observable size of voids is limited by the $\mu \mathrm{CT}$ spatial resolution of $2 \mu \mathrm{m}$. It is considered that a void can't be observed if its size doesn't excess twice the spatial resolution, i.e. $4 \mu \mathrm{m}$. The shape factor distribution of voids, Fig. 13c, shows that the majority of voids are elongated (shape factor superior to 1 and inferior to 2.2) while $17 \%$ of voids have a near spherical morphology. This is a key point that will be discussed further since the mechanism of void formation is generally related to their morphology $[33,35]$.

\subsection{Relationship between spatial distribution of voids and scanning strategy}

The scanning pattern was 3D graphically modelized as shown in Fig. 14a. Green and yellow bands represent either the path of the laser spot center, either the overlay zones between two laser paths. Green bands with an angle of $45^{\circ}$ with respect to the $x$-axis represent the odd deposited powder layers while the yellow bands with an angle of $-45^{\circ}$ represent the even layers. Fig. 14b shows the (XY) plane view of Fig. 14a. The scanning strategy of odd and even layers are superposed and forms a grid pattern. Fig. 14c is the (XY) planar projection of the 3D $\mu \mathrm{CT}$ of voids represented Fig. 13a, and Fig. 14d its enlargement delimited by the dotted lines of Fig. 14c. In Fig. 14c, void distribution describes the same pattern than the scanning strategy observed in Fig. 14b. In Fig. 14d, the pattern characteristic distances and angles are exactly the same than those of the scanning strategy. As a consequence, the void distribution is closely linked to the scanning strategy.

The 3D representation of the scanning tracks or overlay zone, along the (YZ) plane and rotated of $45^{\circ}$ with respect to the z-axis give additional information (Fig. 15). Indeed, bands in Fig. 15a completely fulfill the projected surface on the (YZ) plane, thus voids can be located everywhere on their projected surface which explains that no specific arrangement of voids can be found on Fig. 15c. Similarly, Fig. 15b and Fig. 15d are the (YZ) planar projection of the 3D model and the $\mu \mathrm{CT}$ model respectively, with a rotation of $45^{\circ}$ along the 
z-axis. For more clarity, the orange arrow in Fig. 14b shows the perpendicular direction of the plane of Fig. 15b and Fig. 15d. In Fig. 15b, green bands have an orthogonal orientation while the yellow bands have an orientation parallel with respect to the projection plane. Thus, the projected length of the green bands is larger than the yellow bands, increasing the probability of the projected green areas to contain voids. Similarly, because of the geometry of the 3D model, higher is the lateral distance from the central dotted line, higher the projected length of the yellow and green bands decreases, and thus the probability of projected band area to contain voids will decrease. These remarks explain the vertical line pattern observed in Fig. 15d, where the concentration of projected voids decreases when the lateral distance from the center of the projection increases. As a consequence, a strong correlation between the scanning strategy and the void distribution is observed. In the knowledge of the authors, no such correspondence was pointed out in the literature between scanning strategy and 3D void distribution even if the scanning strategy was shown to influence both the morphology of grains and the density of voids $[7,31,40]$.

\subsection{Void location with respect to the laser path}

Fig. 16a shows the fracture surface of the FS-XY sample where black lines and red areas represent the overlay zones and porosity respectively. Fig. $16 \mathrm{~b}-\mathrm{d}$ are the magnification of the white rectangular zones numbered 1 to 3 . The porosities are bordered in red and the blue arrows show the laser path direction and localization deduced from the laser tracks within each void. The axis of symmetry of the overlay zones represented by the black lines and obtained from the laser path, allow assessing the position of voids with respect to the laser path. It is important to note that (i) the pattern defined by the axis of symmetry of the overlay zones (Fig. 16a) is consistent with that one of the scanning strategy, (ii) the voids are mainly localized on the overlay zones (Fig. 16a), (iii) the fracture surfaces show a mix of ductile and brittle failure mode as already observed by some authors $[19,30,41,42]$.

The morphology and orientation of 719 voids were analyzed as a function of their location in several areas of the FS-XY specimen fracture surface. Voids were firstly classified in 6 morphological groups. Fig. 17a- $f$ and Fig. 17g-I show the 2D and 3D void morphological aspect of each group obtained from fracture surfaces of the FS-XY sample and the $\mu \mathrm{CT}$ results obtained from the YZO sample respectively. All oriented morphologies are systematically oriented along either the $\mathrm{N}-1$ layer or the $\mathrm{N}$ layer laser path direction showing the significant influence of the scanning strategy on void orientation. The " $\mathrm{I}$ " type is defined as a stick like and very oriented morphology (Fig. 17a, g) while the " $O$ " type is a "near-spherical" or "square" like and not very oriented morphology (Fig. 17b, h). The "B" type (Fig. 17c, i) morphology is bottle like oriented morphology. The " $\mathrm{L}$ " type is an oriented morphology along a principal direction but with some short arms along a secondary direction (Fig. 17d, j). The " $\mathrm{H}$ " type is a morphology where no pronounced orientation can be attributed and which is compound of oriented and generally thin arms along both the N-1 and the $\mathrm{N}$ layer laser path direction (Fig. 17e, k). Finally, the "P" type is a massive and not very oriented morphology (Fig. $17 f, I)$.

Among the 719 statistically counted voids, the "O" and "I" type are the two dominant morphologies, representing $44.0 \%$ and $29.0 \%$ of voids respectively while the " $\mathrm{P}$ " and " $\mathrm{H}$ " type morphologies are considerably less represented (3.0\% and $7.0 \%$ respectively). Regarding the " $\mathrm{O}$ " type morphology, the value of $44 \%$ is a slightly higher than the volume fraction of voids obtained by $\mu C T$ and having a spherical morphology (see Section 3.3). This can be explained by two main reasons. First, one corresponds to a bidimensional measurement on a fracture surface while the other one corresponds to a three-dimensional measurement on a smallest volume. Second, the criterion of sphericity used to define the morphology is more restrictive in the case of $\mu \mathrm{CT}$ measurements. 
The distribution of voids as a function of the location of their geometric center was also considered. The "P" and " $\mathrm{H}$ " type morphologies were not taken into consideration due to their complex shapes that make difficult to interpret their location. However, on 643 remaining voids, $75.9 \%$ are located on the intersection between the $\mathrm{N}-1$ projected and the $\mathrm{N}$ overlay zones, $20.1 \%$ are located in the $\mathrm{N}$ overlay zones, $3.7 \%$ are located on the projected $\mathrm{N}-1$ overlay zones and $0.3 \%$ are outside of an overlay zone.

It is worth noting that a void located on a $\mathrm{N}$ overlay zone can be attributed to a lack of energy to melt the powder layer, induced by the lower energy at the periphery of the laser spot, while a void located in an N-1 projected overlay zone can be linked to a too thick stack of powder to be completely melt (see Fig. 18). However, most of voids are shown to be located on both the N-1 projected and N overlay zones, but more voids are located only on the $\mathrm{N}$ overlay zones compared to the $\mathrm{N}-1$ overlay zones. As a consequence, the main mechanism of void generation can be reasonably attributed to the insufficient energy provided at the laser spot periphery. In that case, the too high thickness of powder can be considered more as an aggravating factor. These mechanisms are similar to those mentioned for the EBM process by Gong et al. [35].

These two mechanisms are relative to the same group of mechanisms i.e. a lack of energy provided to the powder material, resulting to a lack of fusion of the powder. However, different morphologies of voids were observed, passing through the near spherical voids to complex or massive morphologies. Contrary to what Gong et al. suggested [35], one type of void morphology is not necessarily limited to one mechanism of void formation, and several kinds of void morphologies can be attributed to a same mechanism.

The results of the statistical study also show that the morphology of voids depends on the location of their geometric center. Indeed, when a void is localized on a N-1 projected overlay zone or on a N overlay zone, the "I" stick like type is the most dominant morphology. However, when a void is located on the intersection of the $\mathrm{N}-1$ projected and the $\mathrm{N}$ overlay zone, the most dominant morphology is the " $\mathrm{O}$ " unoriented type one. These results show that when only one mechanism of void formation is contributing, the very oriented "I" type morphology is preferentially formed whereas the coupling of the two-mentioned mechanisms will preferentially form unoriented " $O$ " type morphology. Void formation mechanisms and their coupling have thus a significant influence on the selection of void morphology. From a general manner, oriented voids are almost systematically oriented along one of the laser path direction. Voids located on $\mathrm{N}-1$ projected overlay zones are predominantly oriented along the N-1 layer laser path direction. Similarly, voids located on $\mathrm{N}$ overlay zones are for the most part oriented along the $\mathrm{N}$ layer laser path direction. But voids located on the intersection between the $\mathrm{N}-1$ projected and $\mathrm{N}$ overlay zones are predominantly unoriented and exclusively correspond to the " $\mathrm{O}$ " type morphology. Among oriented voids, the $\mathrm{N}$ laser path direction is the predominant orientation, showing once again the more significant contribution of the first mechanism mentioned in Fig. 18.

\subsection{Effect of void distribution on tensile properties and fracture behaviour}

Six as-built Ti-6AI-4V SLMed samples were tensile tested along the $\mathrm{x}$-axis. The corresponding stress-strain curves are presented Fig. 19. Ultimate tensile stress (UTS) and ultimate elongation are very disparate and vary from $740 \mathrm{MPa}$ to $1220 \mathrm{MPa}$ and from $0.63 \%$ to $1.85 \%$ respectively. These elongations values are far lower than those observed by Simonelli et al. [18] for near fully dense SLMed Ti-6Al-4V parts, showing the presence of an early breaking phenomenon probably due to the presence of high fraction and density of porosities having a substantial size [43]. In that case, the growth and coarsening of preexisting defects would be the fracture mechanism. The presence of the oriented "I" type morphology formed by a lack of energy could be more detrimental for mechanical properties than those having a spherical morphology [44]. There are several possible reasons for this. Firstly, the local curvature of voids influences the stress concentration factor and then both initiation and propagation of fracture. All being the same, the impact is expected to be 
greater when voids are elongated. Second, the orientation of voids with respect to the loading direction may play an important role. A stress applied along the transversal direction of voids opens up pores whereas a stress applied along the longitudinal direction of pores tends to close and elongate the void until the stress applied exceeds the limit of stress resistance [23]. As a partial conclusion, both the morphology and orientation of voids that depend, in turn, on the mechanism of formation of porosities can be suspected to have an influence on resulting properties. This would explain the anisotropy sometimes encountered by some authors between vertically and horizontally SLM manufactured parts [22,30]. It is interesting to note that both void morphology and their orientation are straightly correlated to the scanning strategy. It can thus be suspected an influence of the scanning strategy on the anisotropy of mechanical properties and the fracture behaviour as already observed Kudzal et al. for steel alloys [31].

Fig. 20a shows the whole $\mu \mathrm{CT}$ view of the FS-XY tensile tested sample after failure. The corresponding stressstrain curve is given by the curve number 6 in Fig. 19. Fig. 20b corresponds to the dual-view of the sample, with the fracture surface at the top part and the void distribution at the bottom part. The black lines show two directions of void alignment (direction 1 and direction 2). The blue dotted arrow points toward a canyon like-shape, oriented along direction 1 on the fracture surface. Fig. 20c and Fig. 20d are the (XY) plane view of two slices of the fracture surface and the projection of voids. The black lines show the two corresponding directions of the void alignment in the (XY) plane. The blue dotted lines show the propagation path of several cracks. The crack path broadly follows the alignment direction of voids. However, as inter-lamellar fracture has been reported, the contribution of pores in fracture mechanism is questionable. One can indeed raise the question of the influence of needles (or laths) boundaries on the cracks propagation. Upon cooling, $\beta$ phase transforms to $\alpha^{\prime}$-martensite for high cooling rate (above $410^{\circ} \mathrm{C} / \mathrm{s}$ ). The newly formed hexagonal phase has a clear crystallographic relationship with parent $\beta$ phase that dictates the $\alpha^{\prime}$ preferential growth orientation and martensitic needles (or laths) are generally observed to be inclined of about $40^{\circ}$ with respect to the build direction. $[45,46]$. However, it can be highly suspected that crack formation is greatly affected by void distribution and therefore by the scanning strategy for three reasons at least. First, most of cracks observed perfectly follow the alignment of pores (see Fig. 20. B). Second, cracks propagate in orthogonal directions (at $90^{\circ}$ ) or in parallel directions (at $180^{\circ}$ ) to the (XY) plane (see Fig. 20. b). We did not observe any direction of propagation at $40^{\circ}-45^{\circ}$ or in multiple direction as it would be imposed by the different variants of martensite needles. Finally, the total surface area occupied by voids in the fracture surfaces of the FS-XY sample was measured to be 17 times higher than the one measured in the MP-XY sample ( $8 \%$ vs $0.48 \%)$. In other words, it can be deduced that cracks preferentially go through the void network. Furthermore, as voids were shown to be mainly located on the overlay zones, it can be suspected that crack path is confined on the overlay zones. Similarly to this study, Kudzal et al. [31] found for steel SLMed parts, some cracks propagated along the melt pool boundaries. It is however difficult to conclude about the role of voids on the mechanisms of both initiation and propagation. Either way, the influence of voids on mechanical properties was confirmed for a volume fraction as low as 0.48 vol\%. The process parameters can be modified in order to reduce or prevent any formation of defects. It is well known that increasing laser power and decreasing laser scanning speed lead to increase both the width and the depth of the melt pool. In that case, the overlapping is promoted and the formation of defects encountered in this study is restrained as observed by Tang et al. [47]. The same effect can be anticipated if the hatch spacing is reduced and the layer thickness is thinner $[35,48]$. The effect of spot size is not linear. An increase of spot size enhances the overlapping and, consequently, the formation of voids by lack of fusion would be reduced. An opposite effect can be expected above a certain size since the melt pool would not be enough deep to make a continuity with the previous layer according to results of Kasperovich et al. [33]. 


\section{Conclusions}

An original approach based on 2D fracture surfaces and 3D X-ray tomography analysis was applied in selective laser melting of Ti-6Al-4V. It provides clarifications regarding both the mechanisms of porosity formation and its influence on mechanical properties. The main conclusions can be summarized as follow:

(1) 3D spatial distribution, morphology and orientation of voids are straightly linked to the scanning strategy pattern.

(2) Voids are mainly localized on the overlay zones and the results obtained support the lack of energy as the main mechanism of void formation.

(3) Both the morphology and the orientation of voids depend on their 3D location.

(4) The un-oriented " $O$ " type is the dominant void morphology, followed by the oriented "I" type morphology. These results show that un-oriented void morphology can be also formed by a lack of energy also.

(5) Tensile properties and crack path are shown to be affected by the presence of voids and their 3D distribution. The presence of porosities makes the sample less ductile, more brittle and the crack paths follow the alignment directions of voids.

\section{Acknowledgements}

This research was funded by We are-3D Materials and Prismadd Grenoble.

\section{References}

1. H. Attar, K.G. Prashanth, A.K. Chaubey, M. Calin, L.C. Zhang, S. Scudino, J. Eckert. Comparison of wear properties of commercially pure titanium prepared by selective laser melting and casting processes. Mater. Lett., 142 (2015), pp. 38-41, 10.1016/i.matlet.2014.11.156

2. H. Attar, M. Calin, L.C. Zhang, S. Scudino, J. Eckert. Manufacture by selective laser melting and mechanical behavior of commercially pure titanium. Mater. Sci. Eng. A, 593 (2014), pp. 170-177, 10.1016/j.msea.2013.11.038

3. B. Wysocki, P. Maj, A. Krawczyńska, K. Rożniatowski, J. Zdunek, K.J. Kurzydłowski, W. Święszkowski. Microstructure and mechanical properties investigation of CP titanium processed by selective laser melting (SLM). J. Mater. Process. Technol., 241 (2017), pp. 13-23, 10.1016/i.jmatprotec.2016.10.022

4. E. Chlebus, B. Kuźnicka, T. Kurzynowski, B. Dybała. Microstructure and mechanical behaviour of Ti-6Al-7Nb alloy produced by selective laser melting. Mater. Charact., 62 (2011), pp. 488-495, 10.1016/i.matchar.2011.03.006

5. L.-C. Zhang, H. Attar. Selective laser melting of titanium alloys and titanium matrix composites for biomedical applications: a review. Adv. Eng. Mater., 18 (2016), pp. 463-475, 10.1002/adem.201500419

6. T. Bormann, R. Schumacher, B. Müller, M. Mertmann, M. de Wild. Tailoring selective laser melting process parameters for NiTi implants. J. Mater. Eng. Perform., 21 (2012), pp. 2519-2524, 10.1007/s11665-012-0318-9

7. L. Thijs, F. Verhaeghe, T. Craeghs, J. Van Humbeeck, J.P. Kruth. A study of the microstructural evolution during selective laser melting of Ti-6Al-4V. Acta Mater., 58 (2010), pp. 3303-3312, 10.1016/i.actamat.2010.02.004

8. M. Simonelli, Y.Y. Tse, C. Tuck. Microstructure of Ti-6Al-4V produced by selective laser melting. J. Phys. Conf. Ser., 371 (2012), 10.1088/1742-6596/371/1/012084

9. E.O. Olakanmi, R.F. Cochrane, K.W. Dalgarno. A review on selective laser sintering/melting (SLS/SLM) of aluminium alloy powders: processing, microstructure, and properties. Prog. Mater. Sci., 74 (2015), pp. 401-477, 10.1016/j.pmatsci.2015.03.002

10. H. Schwab, F. Palm, U. Kühn, J. Eckert. Microstructure and mechanical properties of the near-beta titanium alloy Ti5553 processed by selective laser melting. Mater. Des., 105 (2016), pp. 75-80, 10.1016/j.matdes.2016.04.103

11. M. Akita, Y. Uematsu, T. Kakiuchi, M. Nakajima, R. Kawaguchi. Defect-dominated fatigue behavior in type 630 stainless steel fabricated by selective laser melting. Mater. Sci. Eng. A, 666 (2016), pp. 19-26, 10.1016/j.msea.2016.04.042 
12. S. Gorsse, C. Hutchinson, M. Gouné, R. Banerjee. Additive manufacturing of metals: a brief review of the characteristic microstructures and properties of steels, Ti-6Al-4V and high-entropy alloys. Sci. Technol. Adv. Mater., 18 (2017), pp. 584-610, 10.1080/14686996.2017.1361305

13. J.P. Kruth, G. Levy, F. Klocke, T.H.C. Childs. Consolidation phenomena in laser and powder-bed based layered manufacturing. CIRP Ann. Manuf. Technol., 56 (2007), pp. 730-759, 10.1016/i.cirp.2007.10.004

14. R. Boyer, G. Welsch, E.W. Collings. Materials Properties Handbook: Titanium Alloys. ASM International. https://www.asminternational.org/materials-resources/results/-/journal_content/56/10192/06005G/PUBLICATION (1994)

15. A. Yadollahi, N. Shamsaei. Additive manufacturing of fatigue resistant materials: challenges and opportunities. Int. J. Fatigue, 98 (2017), pp. 14-31, 10.1016/j.ijfatigue.2017.01.001

16. W.E. Frazier. Metal additive manufacturing: a review. J. Mater. Eng. Perform., 23 (2014), pp. 1917-1928, 10.1007/s11665-014-0958-z

17. Z.Z. Fang, J.D. Paramore, P. Sun, K.S.R. Chandran, Y. Zhang, Y. Xia, F. Cao, M. Koopman, M. Free. Powder metallurgy of titanium - past, present, and future. Int. Mater. Rev., 0 (2017), pp. 1-53, 10.1080/09506608.2017.1366003

18. M. Simonelli, Y.Y. Tse, C. Tuck. Effect of the build orientation on the mechanical properties and fracture modes of SLM Ti-6Al-4V. Mater. Sci. Eng. A, 616 (2014), pp. 1-11, 10.1016/i.msea.2014.07.086

19. H. Gong, K. Rafi, H. Gu, G.D. Janaki Ram, T. Starr, B. Stucker. Influence of defects on mechanical properties of Ti-6Al-4V components produced by selective laser melting and electron beam melting. Mater. Des., 86 (2015), pp. 545-554, 10.1016/j.matdes.2015.07.147

20. A.W. Prabhu, T. Vincent, A. Chaudhary, W. Zhang, S.S. Babu. Effect of microstructure and defects on fatigue behaviour of directed energy deposited Ti-6Al-4V. Sci. Technol. Weld. Join., 20 (2015), pp. 659-669, $10.1179 / 1362171815 Y .0000000050$

21. E. Tiferet, O. Rivin, M. Ganor, H. Ettedgui, O. Ozeri, E.N. Caspi, O. Yeheskel. Structural investigation of selective laser melting and electron beam melting of Ti-6Al-4V using neutron diffraction. Addit. Manuf., 10 (2016), pp. 43-46, 10.1016/i.addma.2016.02.001

22. X. Zhao, S. Li, M. Zhang, Y. Liu, T.B. Sercombe, S. Wang, Y. Hao, R. Yang, L.E. Murr. Comparison of the microstructures and mechanical properties of Ti-6Al-4V fabricated by selective laser melting and electron beam melting. Mater. Des., 95 (2016), pp. 21-31, 10.1016/i.matdes.2015.12.135

23. T. Vilaro, C. Colin, J.D. Bartout. As-fabricated and heat-treated microstructures of the Ti-6Al-4V alloy processed by selective laser melting. Metall. Mater. Trans. A, 42 (2011), pp. 3190-3199, 10.1007/s11661-011-0731-y

24. E. Wycisk, C. Emmelmann, S. Siddique, F. Walther. High cycle fatigue (HCF) performance of Ti-6Al-4V alloy processed by selective laser melting. Adv. Mater. Res., 816-817 (2013), pp. 134-139, 10.4028/www.scientific.net/AMR.816817.134

25. E. Wycisk, A. Solbach, S. Siddique, D. Herzog, F.W.-P. Procedia undefined. Effects of defects in laser additive manufactured Ti-6Al-4V on fatigue properties, Elsevier (2014). n.d. https://www-sciencedirect-com.docelec.ubordeaux.fr/science/article/pii/S18753892140026X (accessed June 8, 2018)

26. E. Wycisk, S. Siddique, D. Herzog, F. Walther, C. Emmelmann. Fatigue performance of laser additive manufactured Ti6AI-4V in very high cycle fatigue regime up to 109 cycles. Front. Mater. Sci., 2 (2015), 10.3389/fmats.2015.00072

27. T. Vilaro, C. Colin, J.D. Bartout. As-fabricated and heat-treated microstructures of the Ti-6Al-4V alloy processed by selective laser melting. Metall. Mater. Trans. A Phys. Metall. Mater. Sci., 42 (2011), pp. 3190-3199, 10.1007/s11661011-0731-y

28. C. Qiu, N.J.E. Adkins, M.M. Attallah. Selective laser melting of Invar 36: Microstructure and properties. Acta Mater., 103 (2016), pp. 382-395, 10.1016/i.actamat.2015.10.020

29. S. Leuders, M. Thöne, A. Riemer, T. Niendorf, T. Tröster, H.A. Richard, H.J. Maier. On the mechanical behaviour of titanium alloy TiAI6V4 manufactured by selective laser melting: fatigue resistance and crack growth performance. Int. J. Fatigue, 48 (2013), pp. 300-307, 10.1016/j.ijfatigue.2012.11.011

30. H.K. Rafi, T.L. Starr, B.E. Stucker. A comparison of the tensile, fatigue, and fracture behavior of Ti-6Al-4V and 15-5 PH stainless steel parts made by selective laser melting. Int. J. Adv. Manuf. Technol., 69 (2013), pp. 1299-1309, 10.1007/s00170-013-5106-7

31. A. Kudzal, B. McWilliams, C. Hofmeister, F. Kellogg, J. Yu, J. Taggart-Scarff, J. Liang. Effect of scan pattern on the microstructure and mechanical properties of Powder Bed Fusion additive manufactured 17-4 stainless steel. Mater. Des., 133 (2017), pp. 205-215, 10.1016/j.matdes.2017.07.047

32. R. Konecná, L. Kunz, G. Nicoletto, A. Baca. Fatigue crack growth behavior of Inconel 718 produced by selective laser melting. Frat. Ed Integrità Strutt., 10 (2016), pp. 31-40, 10.3221/IGF-ESIS.35.04 
33. G. Kasperovich, J. Haubrich, J. Gussone, G. Requena. Corrigendum to “Correlation between porosity and processing parameters in TiAl6V4 produced by selective laser melting”. Mater. Des., 112 (2016), pp. 160-161, 10.1016/j.matdes.2016.09.040

34. M. Seifi, A. Salem, J. Beuth, O. Harrysson, J.J. Lewandowski. Overview of materials qualification needs for metal additive manufacturing. JOM, 68 (2016), pp. 747-764, 10.1007/s11837-015-1810-0

35. H. Gong, K. Rafi, H. Gu, T. Starr, B. Stucker. Analysis of defect generation in Ti-6Al-4V parts made using powder bed fusion additive manufacturing processes. Addit. Manuf., 1 (2014), pp. 87-98, 10.1016/j.addma.2014.08.002

36. D.D. Gu, W. Meiners, K. Wissenbach, R. Poprawe. Laser additive manufacturing of metallic components: materials, processes and mechanisms. Int. Mater. Rev., 57 (2012), pp. 133-164, 10.1179/1743280411Y.0000000014

37. H. Gong, H.K. Rafi, N.V. Karthik, T.L. Starr, B.E. Stucker. Defect morphology in Ti-6Al-4V parts fabricated by selective laser melting and electron beam melting. Solid Free Fabr. Symp. Symporisum Proceeding (2013), pp. 440-453, 10.1007/s11665-013-0658-0

38. ASTM. B348-13, Standard Specification for Titanium and Titanium Alloy Bars and Billets. (2013), 10.1520/B0348

39. C. Zhao, K. Fezzaa, R.W. Cunningham, H. Wen, F. De Carlo, L. Chen, A.D. Rollett, T. Sun. Real-time monitoring of laser powder bed fusion process using high-speed X-ray imaging and diffraction. Sci. Rep., 7 (2017), pp. 1-11, 10.1038/s41598-017-03761-2

40. L.N. Carter, C. Martin, P.J. Withers, M.M. Attallah. The influence of the laser scan strategy on grain structure and cracking behaviour in SLM powder-bed fabricated nickel superalloy. J. Alloys Compd., 615 (2014), pp. 338-347, 10.1016/j.jallcom.2014.06.172

41. P. Krakhmalev, G. Fredriksson, I. Yadroitsava, N. Kazantseva, A. Du Plessis, I. Yadroitsev. Deformation behavior and microstructure of Ti6AI4V manufactured by SLM. Phys. Procedia, 83 (2016), pp. 778-788, 10.1016/i.phpro.2016.08.080

42. J. Yang, H. Yu, Z. Wang, X. Zeng. Effect of crystallographic orientation on mechanical anisotropy of selective laser melted Ti-6AI-4V alloy. Mater. Charact., 127 (2017), pp. 137-145, 10.1016/j.matchar.2017.01.014

43. M.G. Moletsane, P. Krakhmalev, N. Kazantseva, A. du Plessis, I. Yadroitsava, I. Yadroitsev. Tensile properties and microstructure of direct metal laser-sintered Ti6Al4V (Eli) alloy. South African J. Ind. Eng., 27 (2016), 10.7166/27-31667

44. J. Schijve. Fatigue of Structures and Materials. (2009), 10.1007/978-1-4020-6808-9

45. H.K. Rafi, T.L. Starr, B.E. Stucker. A comparison of the tensile, fatigue, and fracture behavior of Ti-6Al-4V and 15-5 PH stainless steel parts made by selective laser melting. Int. J. Adv. Manuf. Technol., 69 (2013), pp. 1299-1309, 10.1007/s00170-013-5106-7

46. B. Vrancken, L. Thijs, J.-P. Kruth, J. Van Humbeeck. Heat treatment of Ti6Al4V produced by selective laser melting: microstructure and mechanical properties. J. Alloys Compd., 541 (2012), pp. 177-185, 10.1016/i.jallcom.2012.07.022

47. M. Tang, P.C. Pistorius, J.L. Beuth. Prediction of lack-of-fusion porosity for powder bed fusion. Addit. Manuf., 14 (2017), pp. 39-48, 10.1016/j.addma.2016.12.001

48. C. Qiu, C. Panwisawas, M. Ward, H.C. Basoalto, J.W. Brooks, M.M. Attallah. On the role of melt flow into the surface structure and porosity development during selective laser melting. Acta Mater., 96 (2015), pp. 72-79, 10.1016/j.actamat.2015.06.004 


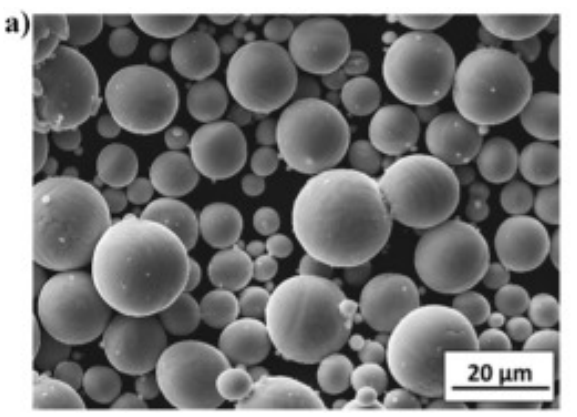

b)

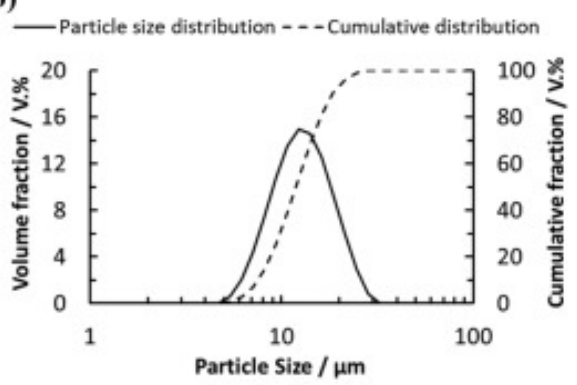

Fig. 1. Ti-6Al-4V input powder. a) SEM image and b) particle size distribution measured by laser diffraction.
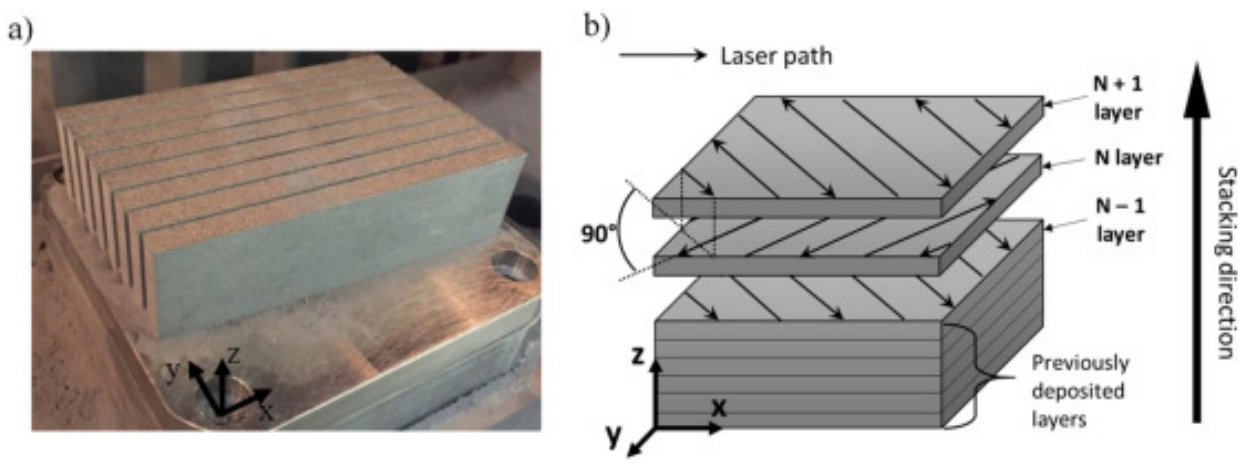

Fig. 2. a) Photography of Ti-6Al-4V SLMed parts and b) the schematic representation of the scanning strategy consisting of straight lines pattern with a rotation of $90^{\circ}$ between each successive layer. The $x, y$ and $z$-axes represent the powder loading direction, the axis of the roller and the layer stacking direction respectively. The black arrows represent the laser path.

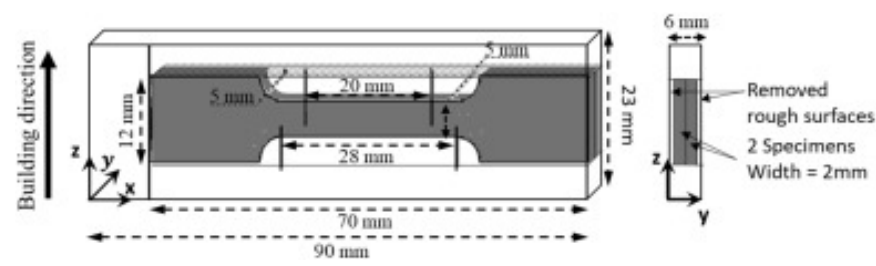

Fig. 3. Schematic representation of the sampling locations and dimensions of the tensile specimens. The tensile specimens were prepared by electrical discharge machining process after removing the rough surface along the (XZ) plane.

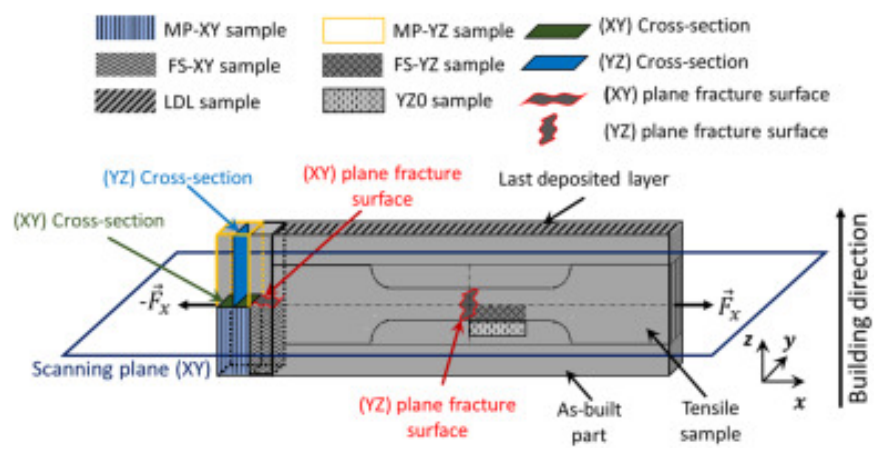

Fig. 4. Schematic representation of mechanically polished (MP), fracture surface (FS), last deposited layer (LDL) and reference (YZO) specimens sampled on the SLM as-build parts. 


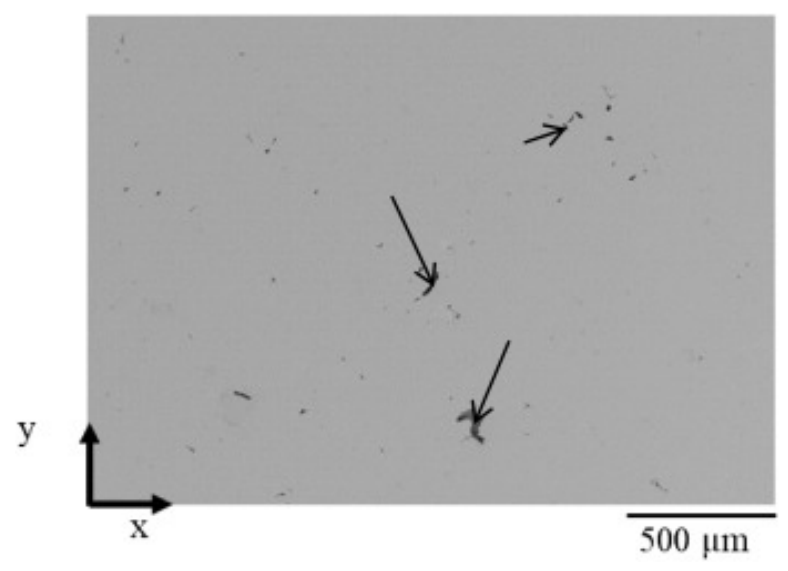

Fig. 5. SEM in backscattered electrons of the (XY) plane cross-section of the MP-XY sample.

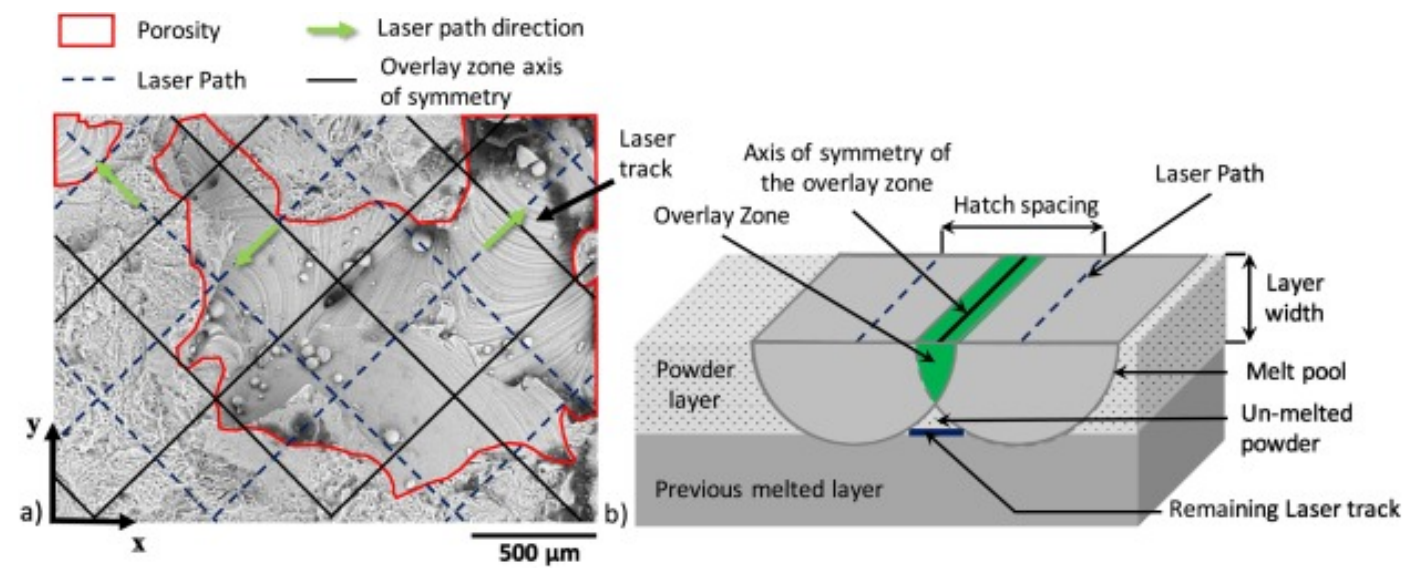

Fig. 6. a) SEM image of the FS-XY sample fracture surface showing two identified and selected voids, their laser track and direction, the deducted laser path and overlay zones. b) schematic representation of the melt-pool showing the laser path and the overlay zone. 


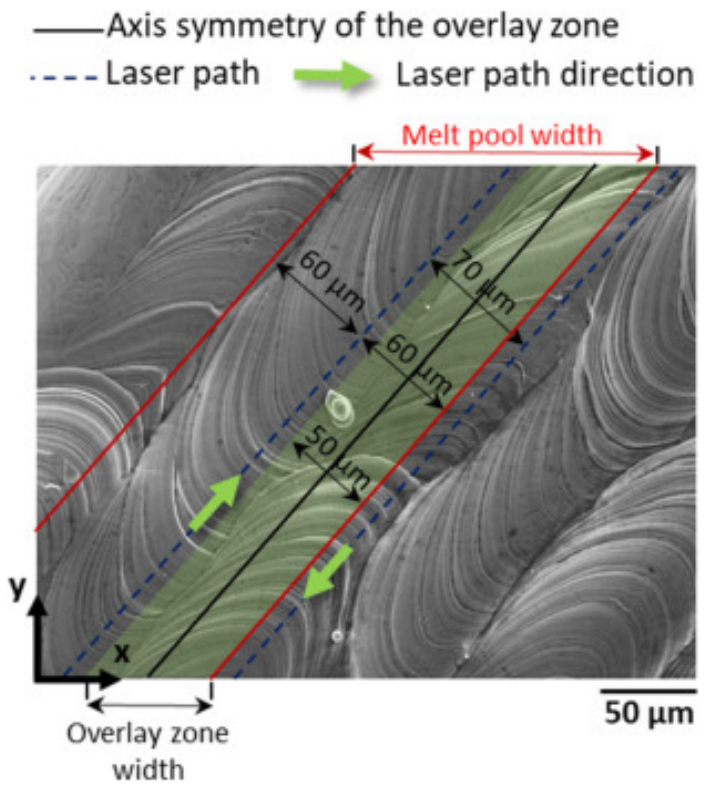

Fig. 7. SEM image of the top surface of the as-built sample. The laser path and the axis of symmetry of the overlay zone were determined. The melt pool and the overlay zone width are measured to be around $120 \mu \mathrm{m}$ and $50 \mu \mathrm{m}$ respectively.

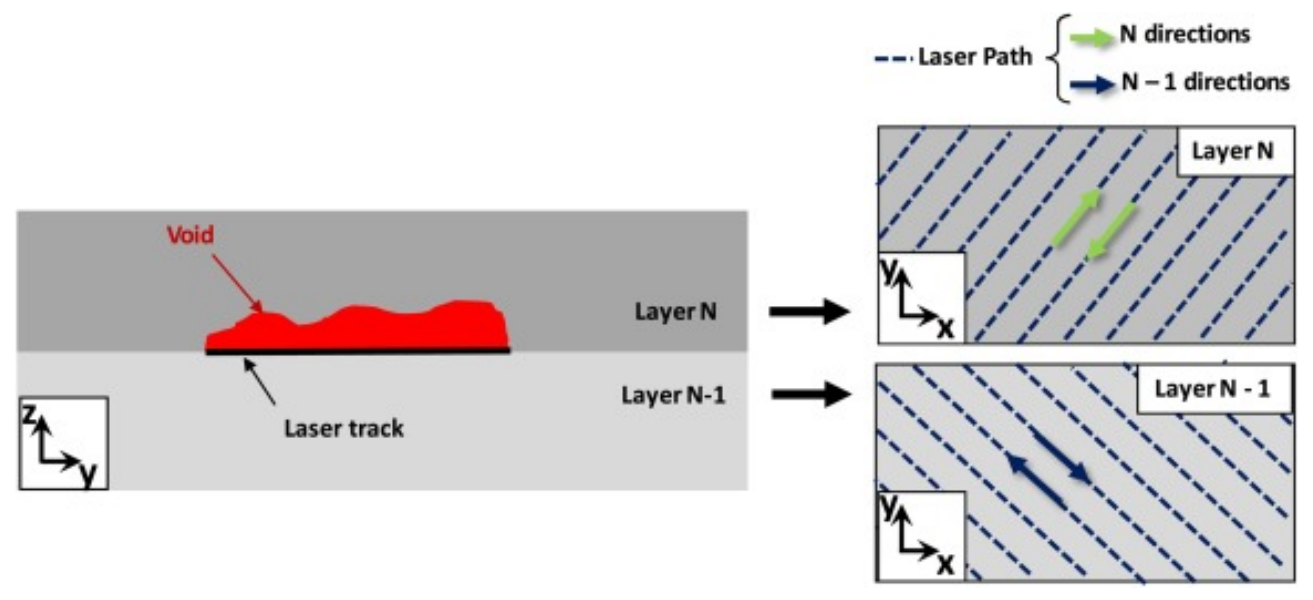

Fig. 8. Schematic cross section of the interface between two layers: Example of $\mathrm{N}$ and $\mathrm{N}-1$ layers and their laser path directions for a considered void.

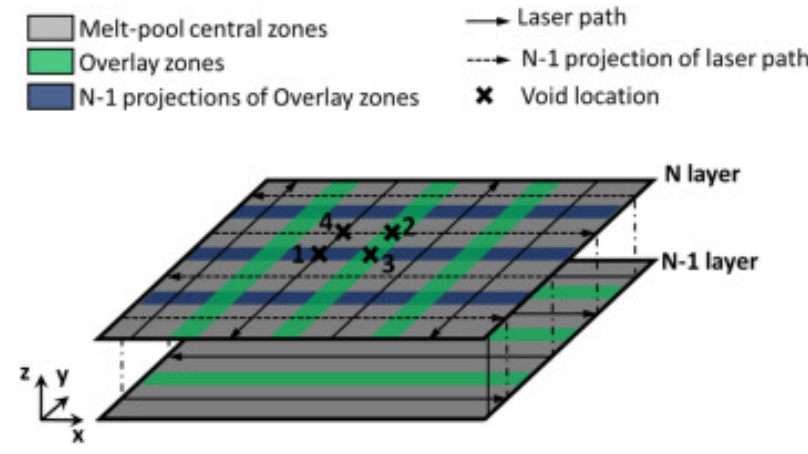

Fig. 9. Schematic representation of the four possible locations of voids: (1) in the N-1 projected overlay zone, (2) in the $\mathrm{N}$ overlay zone, (3) both in the N and N-1 projected overlay zones and (4) outside of an overlay zone. 


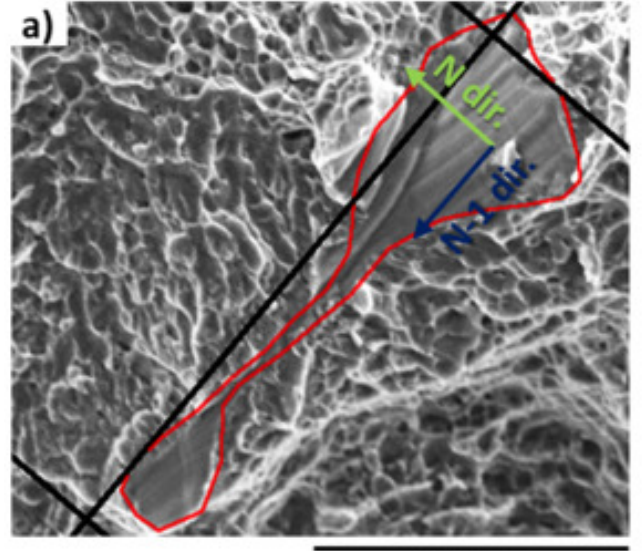

$35 \mu \mathrm{m}$

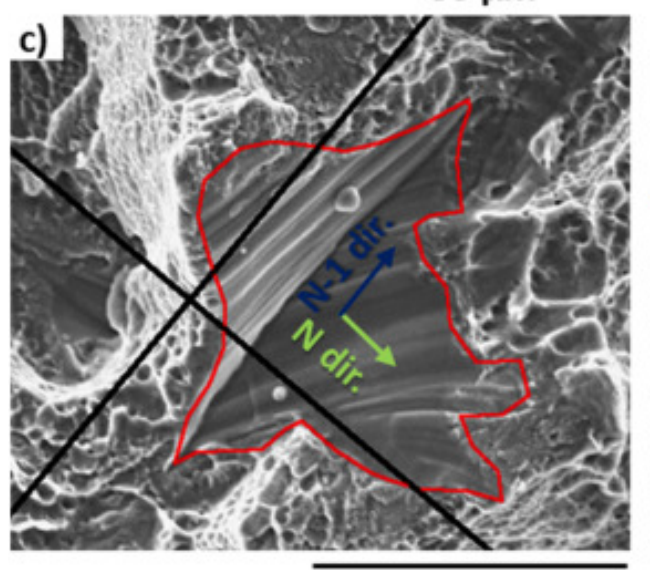

$35 \mu \mathrm{m}$

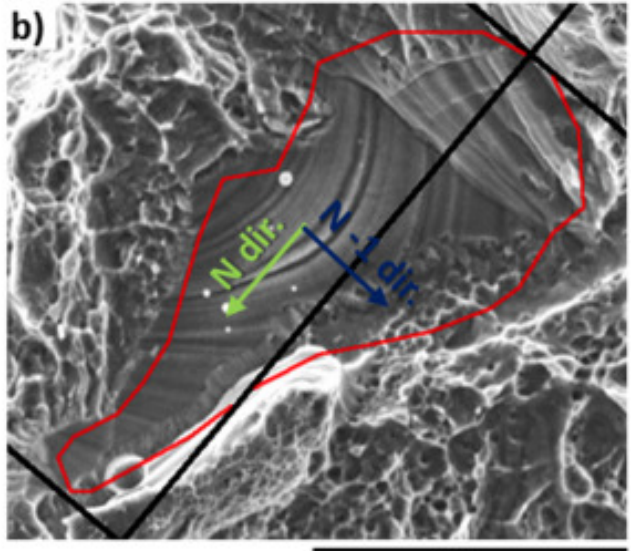

$35 \mu \mathrm{m}$

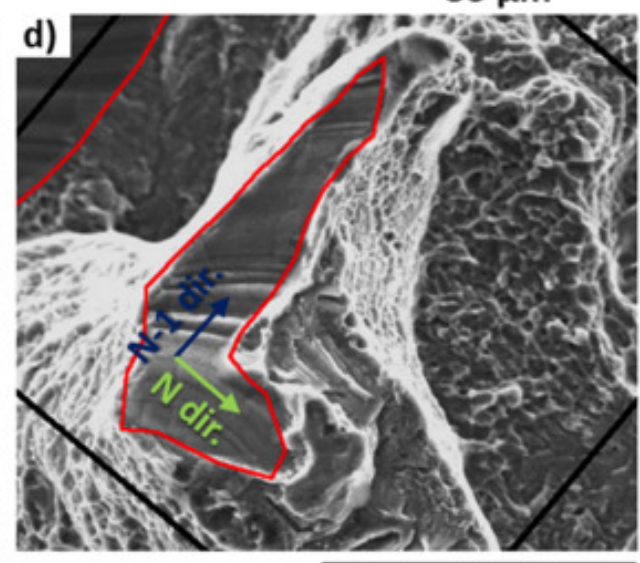

$35 \mu \mathrm{m}$

Fig. 10. SEM images of the fracture surface of the FS-XY sample showing voids located a) on the N-1 overlay zone, b) on the $\mathrm{N}$ overlay zone, $\mathrm{c}$ ) on the intersection between the $\mathrm{N}-1$ projected and $\mathrm{N}$ overlay zones, $\mathrm{d}$ ) and not located on an overlay zone. The axis of symmetry of the overlay zones are represented by the black lines. 


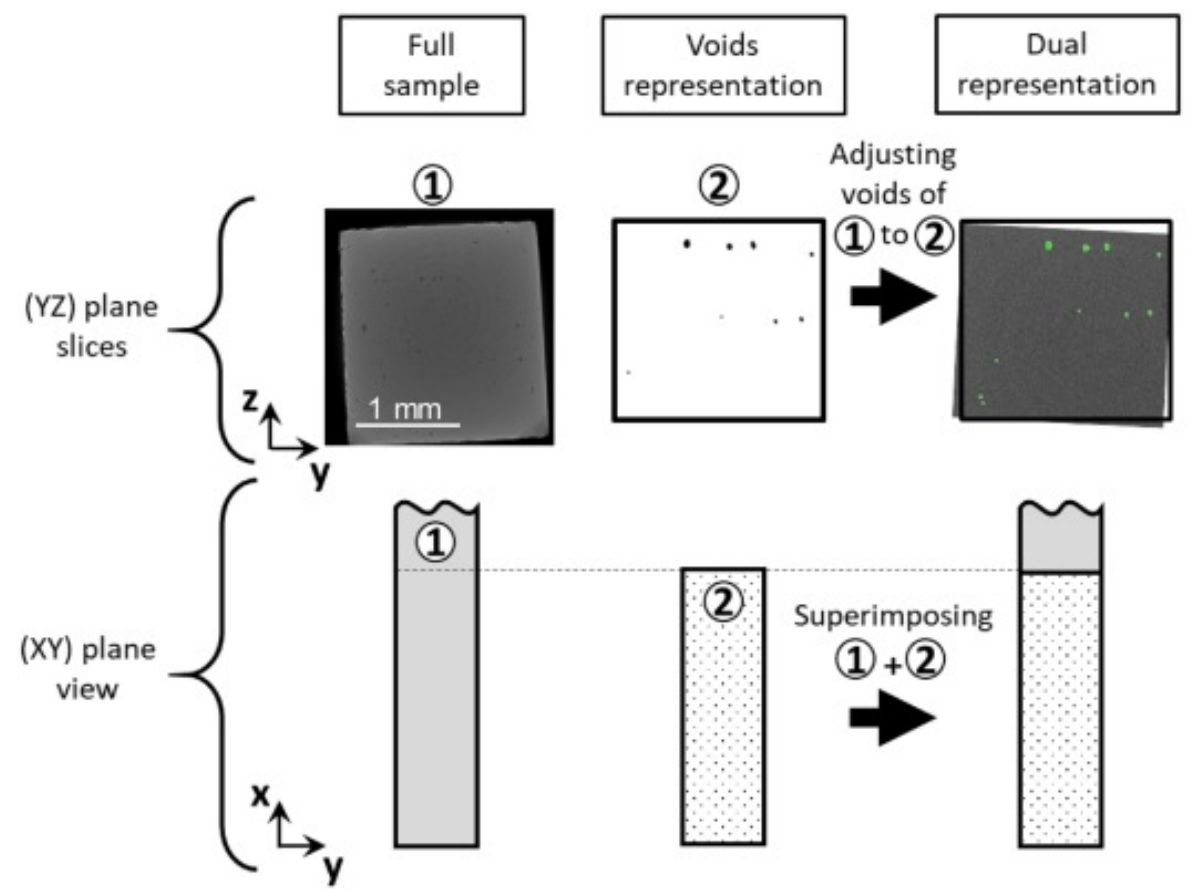

Fig. 11. Methodology to obtain the dual representation composed of the 3D view of the fracture surface of the broken tensile sample and the 3D distribution of voids. The two parts were properly superimposed by matching some common slides. 


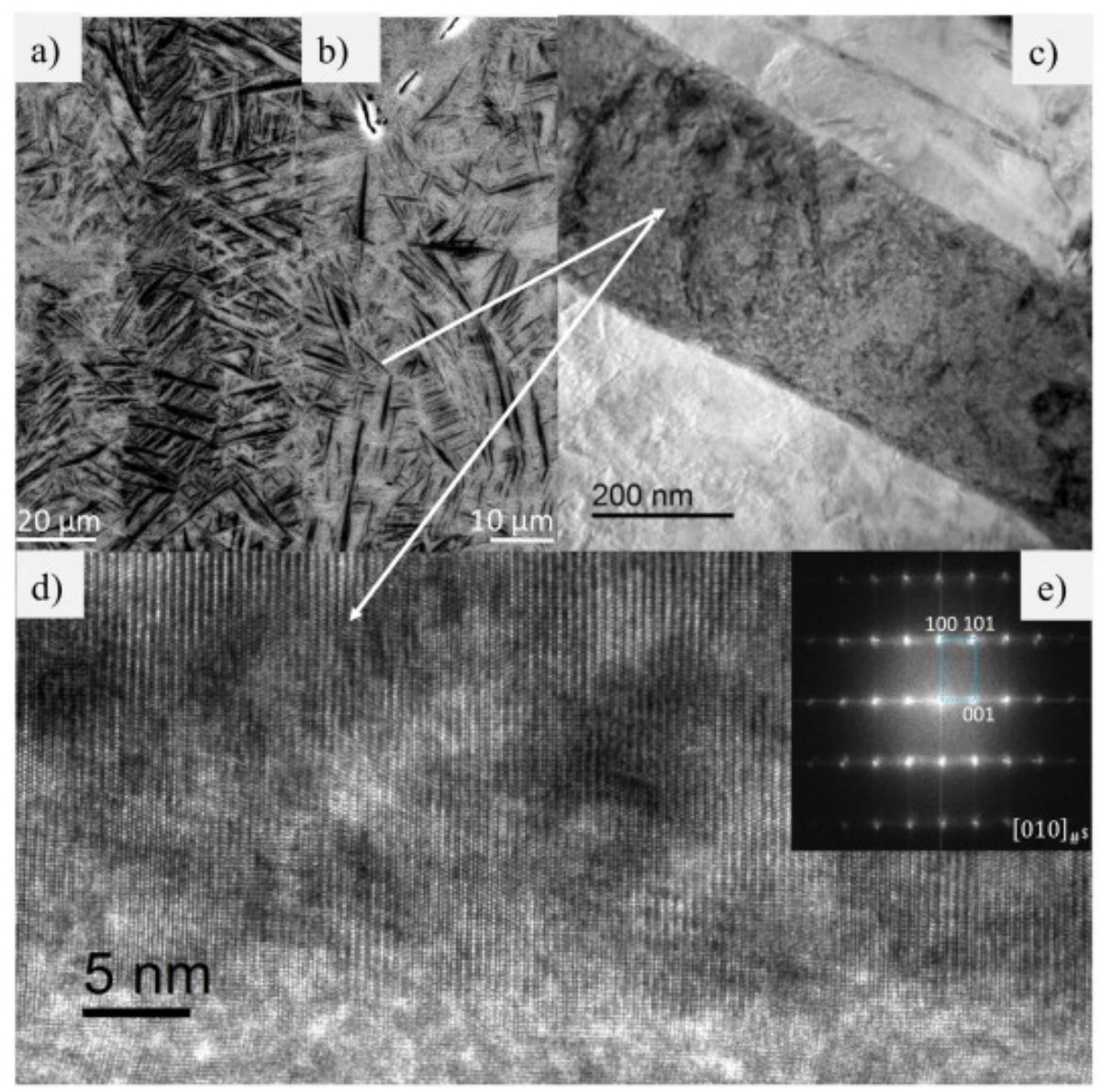

Fig. 12. Microstructure of the SLMed Ti-6AI-4V as built sample. a) SEM image showing the macrostructure of solidification. b) SEM image showing the $\alpha^{\prime}$-martensite needles resulting from the displacive $\beta \rightarrow \alpha^{\prime}$ transformation upon cooling. c) TEM bright field image of a needle of $\alpha^{\prime}$-martensite of about $300 \mathrm{~nm}$ of width. d) High resolution

TEM image of the given $\alpha^{\prime}$-martensite needle. e) Fast Fourier Transform (FFT) along the zone axis [010] $\alpha^{\prime}$ which confirms the presence of a hexagonal crystalline structure with lattice parameters $a=0.252 \mathrm{~nm}, b=0.222 \mathrm{~nm}$ and $\mathrm{c}=0.467 \mathrm{~nm}$. 


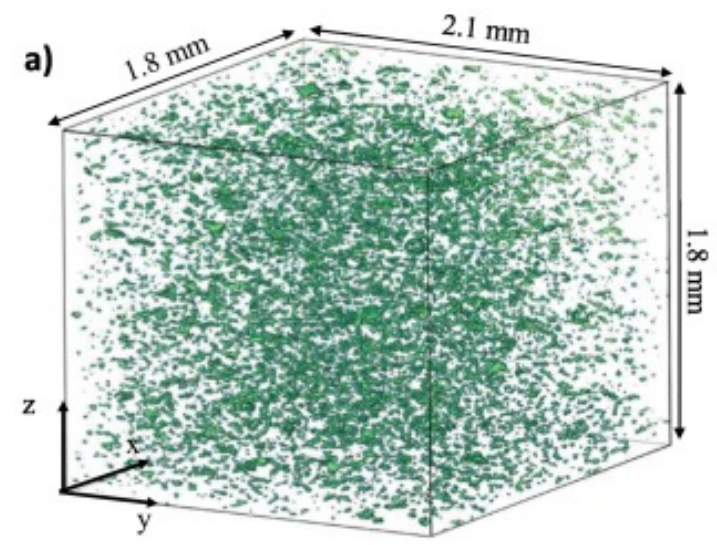

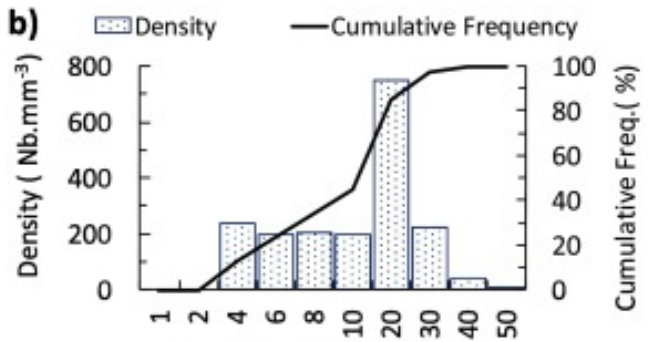

Equivalent Diameter $/ \mu \mathrm{m}$ c)

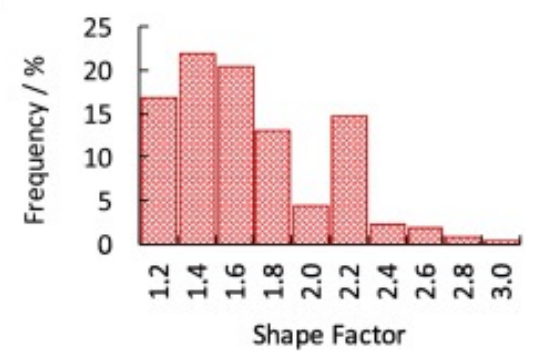

Fig. 13. a) Three-dimensional $\mu \mathrm{CT}$ view of voids in the as-built sample. The volume fraction and the density of voids were respectively measured as 0.48 vol\% and 1866 particle $\cdot \mathrm{mm}^{-3}$. b) Equivalent diameter distribution of voids. c) Shape factor distribution of voids.

a)

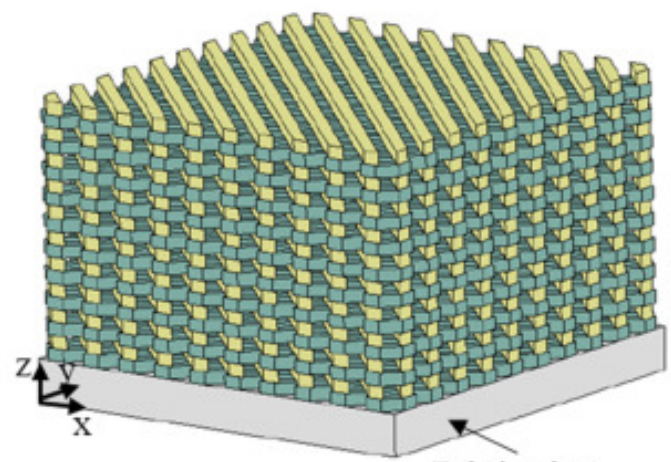

Fabrication

c)

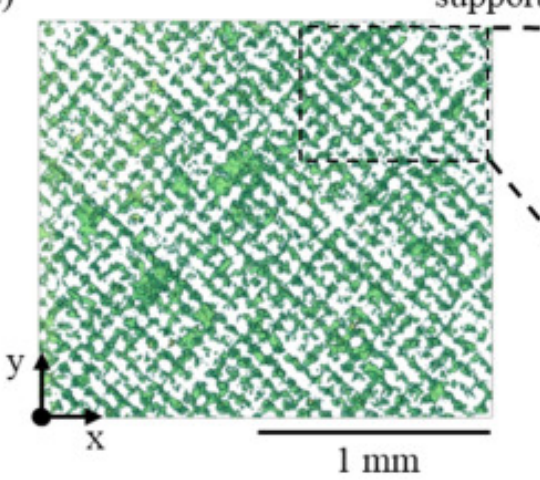

b)

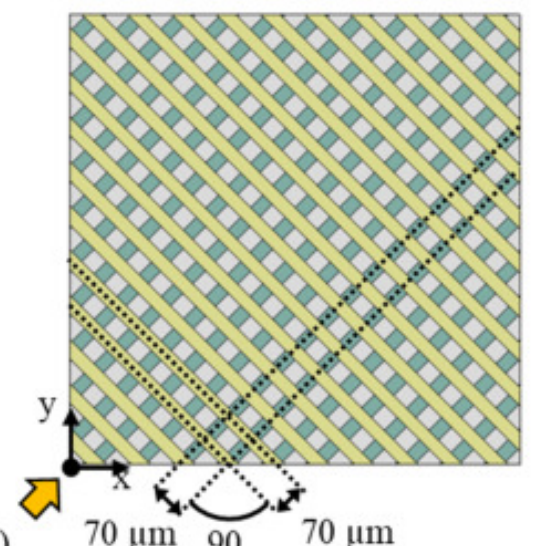

d)

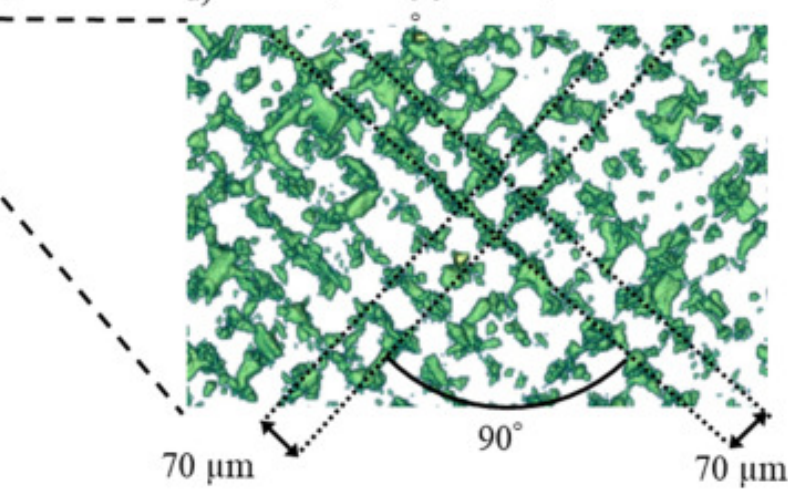

Fig. 14. a) 3D representation of the scanning tracks or overlay zones and b) its projection on the (XY) plane, c) the $\mu \mathrm{CT}$ projection of voids along the (XY) plane and d) its enlargement of the corresponding rectangular defined zone. 


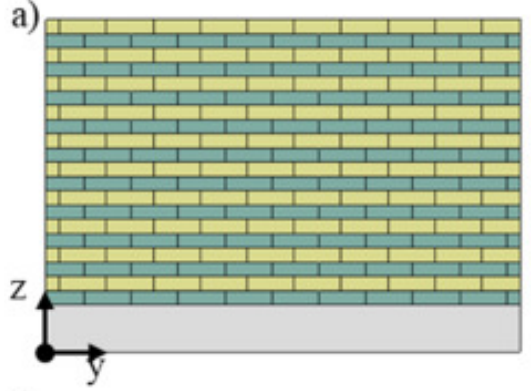

c)

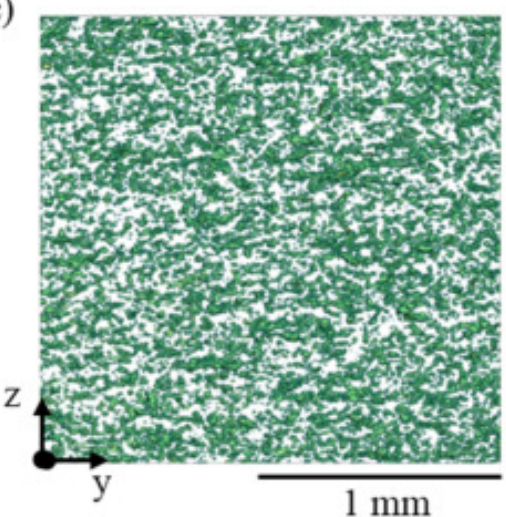

b)

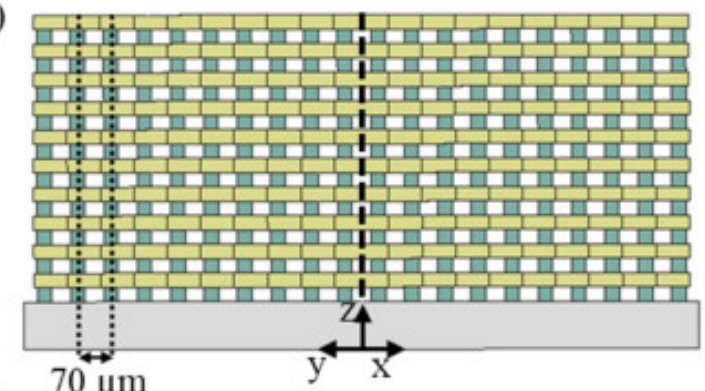

d)

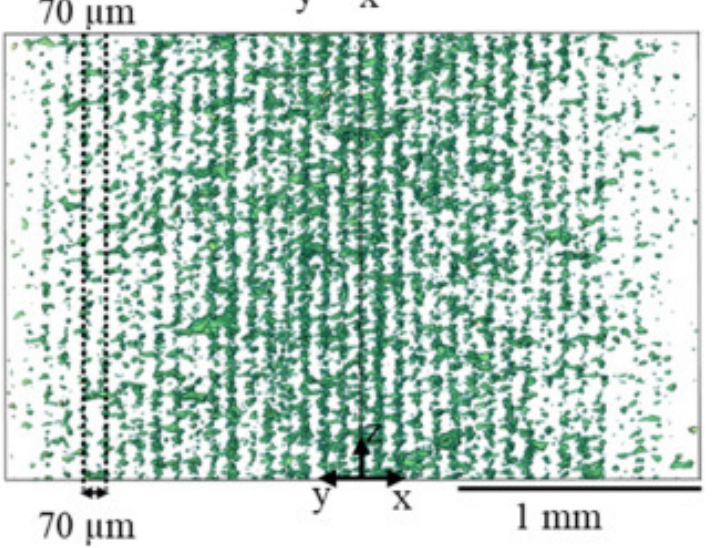

Fig. 15. a) Three-dimensional representation of the scanning tracks or overlay zones view along the (YZ) plane and b) its 45-degree rotation with respect to the Z-axis, c) the X-ray tomography projection of voids along the (YZ) plane and

d) its 45-degree rotation with respect to the z-axis. For more clarity, an orange arrow in Fig. 14b shows the perpendicular direction of the plane of panels $b$ and $d$.

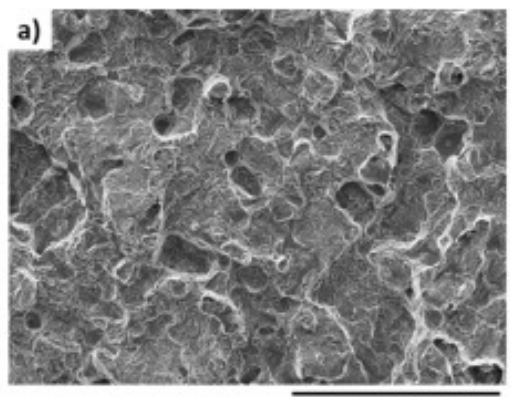

$500 \mu \mathrm{m}$

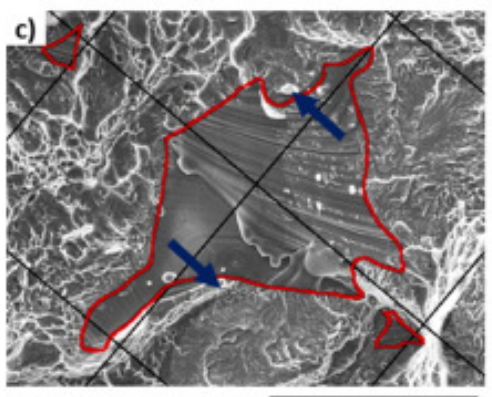

$70 \mu \mathrm{m}$

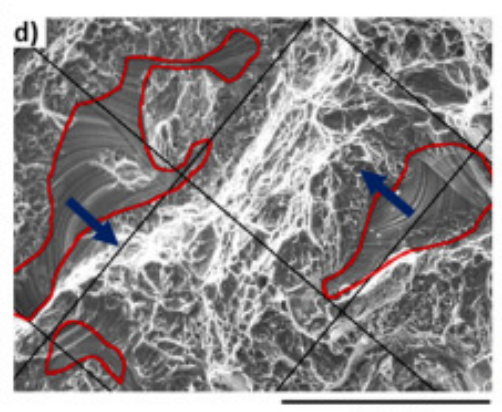

$70 \mu \mathrm{m}$

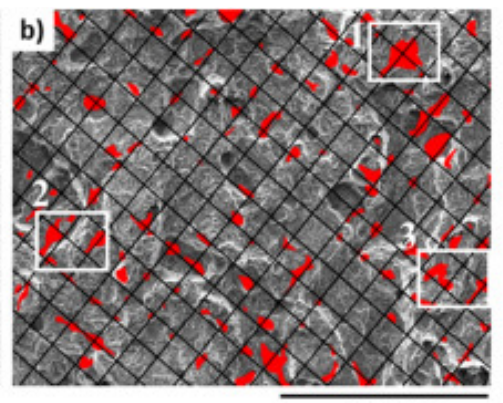

$500 \mu \mathrm{m}$

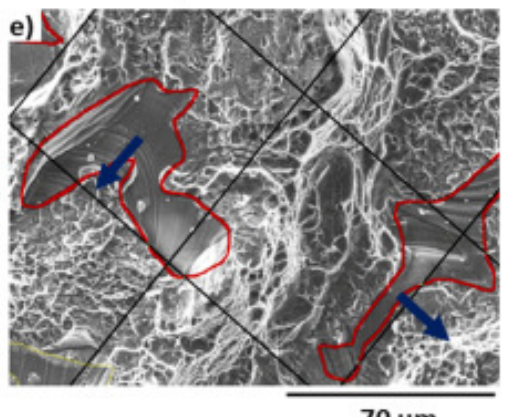

$70 \mu \mathrm{m}$

Fig. 16. a) SEM of the fracture surface of a SLMed Ti-6Al-4V sample tested until fracture and performed along the zdirection. b) Void marking in red color and reconstructed overlay zone axis of symmetry. c) Magnification of zone 1.

d) Magnification of zone 2. e) Magnification of zone 3. Blue arrows show the laser path deduced from the laser tracks within each void and black lines represent the reconstructed overlay zone axis of symmetry. 


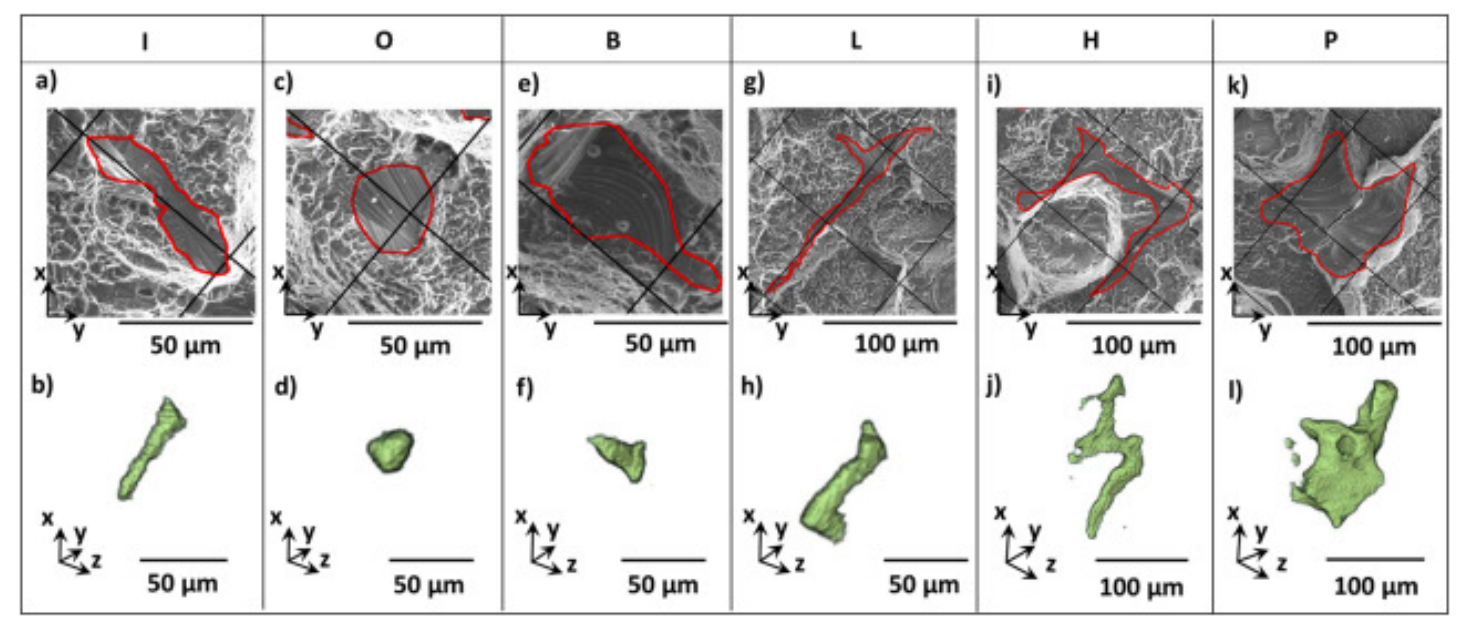

Fig. 17. SEM images of the FS-XY specimen fracture surface and corresponding 3D morphology of voids obtained by $\mu C T$. $(a, g)$ correspond to the "I" oriented type morphology, $(b, h)$ to the " $O$ " un-oriented type morphology, $(c, i)$ to the "B" bottle type morphology, $(d, j)$ to the "L" type morphology with a principal marked orientation and short arms along the perpendicular direction, $(e, k)$ to the " $H$ " type morphology passing through both $N-1$ and $N$ directions and $(f, i)$ to the " $P$ " massive type morphology.

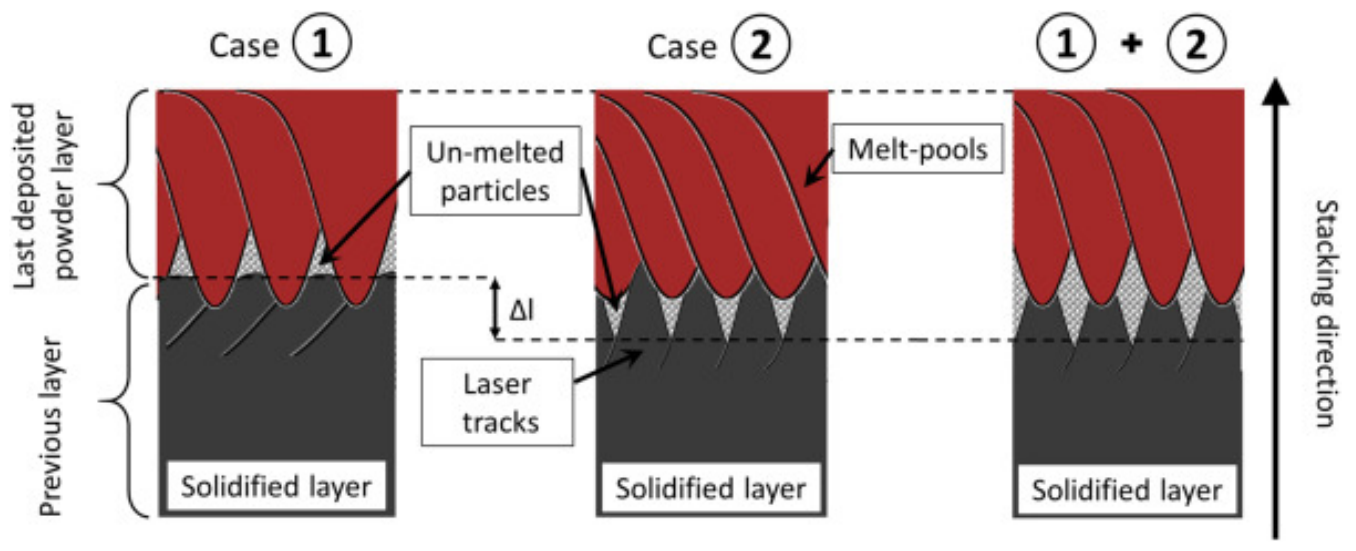

Fig. 18. Schematic representation of the melt-pool showing the two mechanisms of void formation and their coupling. $\Delta \mathrm{l}$ is the difference of layer thickness due to the laser track topology. The first mechanism (1) is the lack of energy provided by the laser at its periphery and the second (2) is the too high thickness of powder to be melt. Dark grey color represents the previously solidified layer ( $\mathrm{N}-1$ layer) containing laser tracks. Red color represents the melted pools after solidification of the new layer ( $\mathrm{N}$ layer). 


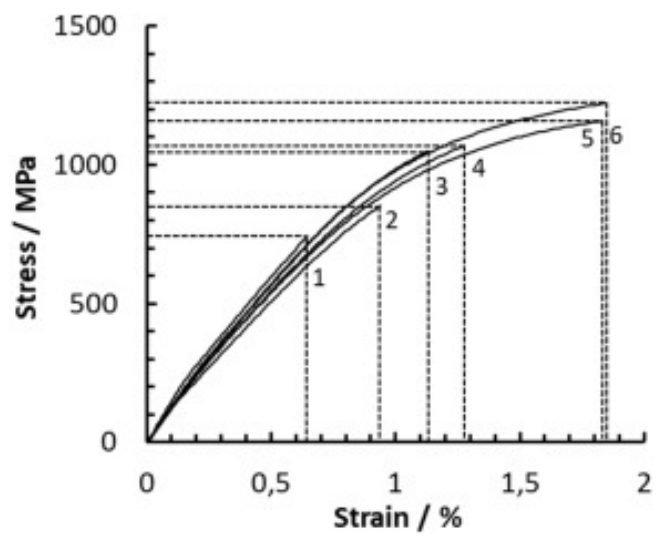

Fig. 19. Stress-strain curves of the as-built Ti-6Al-4V SLMed samples along the $x$-axis.

Table 1

Chemical composition of the Ti-6Al-4V input powder.

\begin{tabular}{llllll}
\hline \multicolumn{6}{l}{ Chemical composition in wt\% } \\
\hline $\mathrm{Ti}$ & $\mathrm{Al}$ & $\mathrm{V}$ & $\mathrm{Fe}$ & $\mathrm{O}$ & $\mathrm{H}$ \\
\hline Bal. & 5.770 & 3.910 & 0.220 & 0.120 & 0.006 \\
\hline
\end{tabular}

Table 2

Laser process parameters used in this study.

\begin{tabular}{lllll}
\hline $\begin{array}{l}\text { Laser power } \\
(\mathrm{W})\end{array}$ & $\begin{array}{l}\text { Laser scanning speed } \\
(\mathrm{mm} / \mathrm{s})\end{array}$ & $\begin{array}{l}\text { Hatch spacing } \\
(\mu \mathrm{m})\end{array}$ & $\begin{array}{l}\text { Spot size } \\
(\mu \mathrm{m})\end{array}$ & $\begin{array}{l}\text { Powder layer thickness } \\
(\mu \mathrm{m})\end{array}$ \\
\hline 41.7 & 400 & 70 & 85 & $\begin{array}{l}\text { Energy density } \\
\left(\mathrm{J} / \mathrm{mm}^{3}\right)\end{array}$ \\
\hline
\end{tabular}


a)

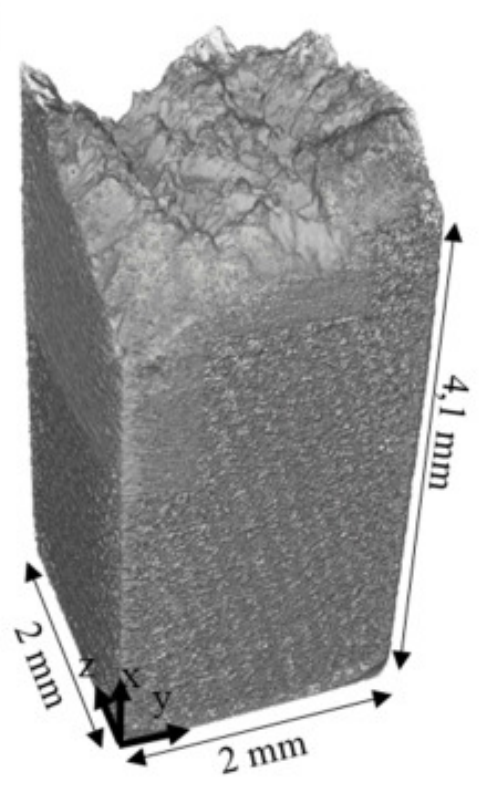

c)

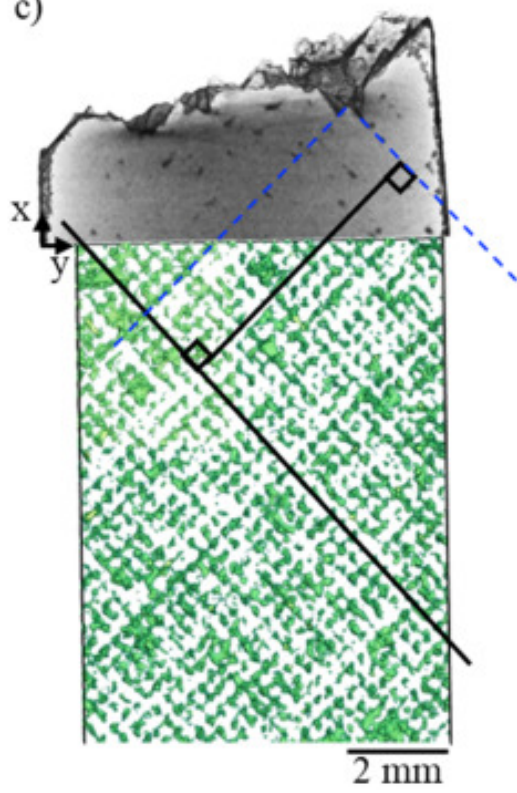

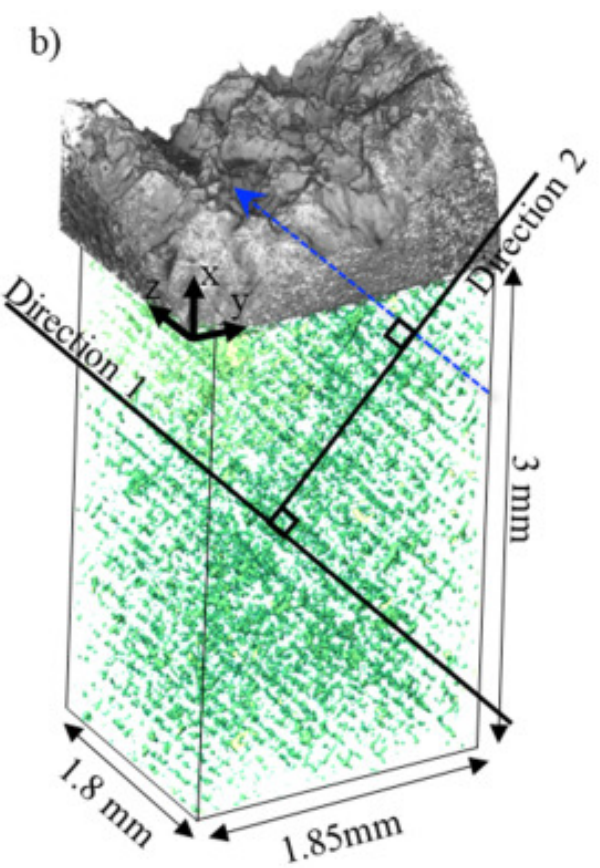

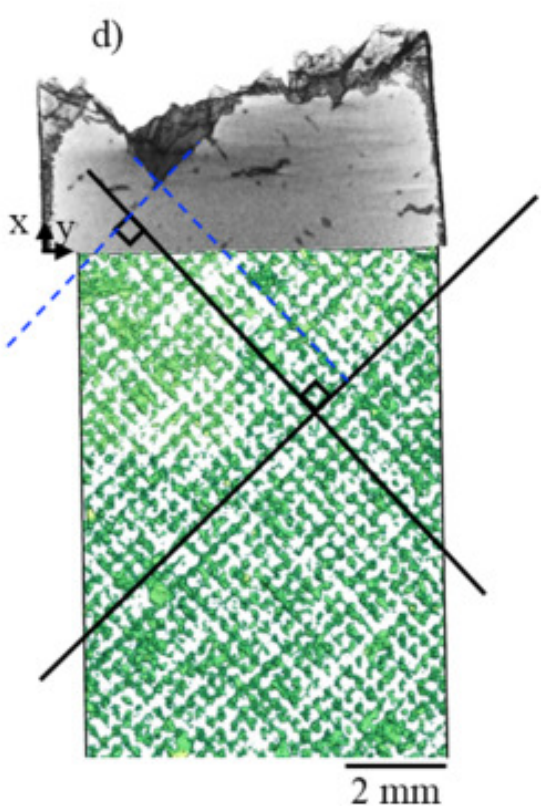

Fig. 20. a) Three-dimensional $\mu C T$ view of the broken tensile sample along $x$-axis. $b$ ) dual-view of the broken tensile sample with the fracture surface at the top part and the 3D void distribution at the bottom part. c) and d) two different $(X Y)$ plane view of two slices of the fracture surface and the projection of voids on the (XY) plane. 